\title{
Shipbuilding and new requirements to reduce the environmental impact of ships: New technological challenges and business opportunities
}

Publio Beltrán ${ }^{1}$

\begin{abstract}
New and increasingly demanding requirements of reducing the environmental impact of all types of ships from all countries, along with regulatory institutions like the new "Green Policy" of the European Union, leads to the development of a series of regulations/directives, which will immediately affect both the owner and the builders worldwide. This requires introducing modifications in the vessel design to fulfill these requirements and, ultimately, improve their exploitation while avoiding penalties and/or restrictions. Awareness of these requirements by some Spanish owners has allowed Spanish shipbuilding to be positioned strategically at the forefront of technology to fulfill these requirements. This work, after a review of those Directives affecting ship design, focuses on the presentation of the results obtained in two Ro-Ro Vessels. These vessels, given their design and performances, are a "technological reference" in the new scenario of high environmental performance requirements: Noise and vibrations on board, noise radiated to the harbor, and noise radiated to the water.
\end{abstract}

Key words: Ship Environmental Impact Reduction; Noise \& Vibrations; Underwater Radiated Noise.

\section{Resumen}

Los nuevos y cada vez más exigentes requerimientos de reducción del impacto medioambiental de todo tipo de buques por parte de todos los países y organismos reguladores, como la nueva "Política Verde (Green Policy)" de la Unión Europea, llevan aparejados la aparición de una serie de reglamentaciones/directivas que afectarán, de forma inmediata, tanto a los armadores como a los constructores en el ámbito mundial. Ello hace imprescindible la introducción de modificaciones en los diseńos de los buques que permitan cumplir con los nuevos requerimientos y en definitiva mejorar su explotación, así evitando penalizaciones y/o restricciones. La sensibilización de algunos armadores espańoles con estos requerimientos ha permitido a la construcción naval Española posicionarse en la vanguardia y situarse estratégicamente para dar respuesta tecnológica a estos requerimientos. Este trabajo, tras un repaso de las directivas que afectarán al diseño de los buques, se centra en la presentación de los resultados obtenidos en dos buques RO-RO. Buques que por su diseńo y prestaciones, constituyen un "referente tecnológico" en el nuevo escenario de requerimientos de altas prestaciones medioambientales: Ruidos y vibraciones a bordo, ruido radiado al puerto y ruido radiado al agua.

Palabras claves: Reducción Impacto Ambiental de los Buques; Ruidos \& Vibraciones; Ruido Radiado al agua.

Date Received: January 14th, 2011 - Fecha de recepción: 14 de Enero de 2011

Date Accepted: March 10th, 2011 - Fecha de aceptación: 10 de Marzo de 2011

\footnotetext{
${ }^{1}$ Naval Architect and Marine Engineer. Director TSI- Técnicas y Servicios de Ingeniería, S. L. Madrid, Espańa. e-mail: publiobp@tsisl.es
} 


\section{Introduction}

Growing social interest on the importance of Control, Monitoring, and Improvement of the environment has been the stimulus for different states to respond to this current demand. Like many other countries, the European Union (EU), also sensitive to these claims, has started the socalled "Green Policy", whose main target is to establish directives or/and requirements to improve and maintain the environment. Withinthis new "Green Policy", the EU has identified "ambient noise" [1] as one of the most critical factors to control, being all types of transport (land, air, and sea) the main polluting agents. Consequently, Noise and Vibration reduction in all types of transport constitutes one of the main objectives in the environmental improvement policy defined by the EU and the other countries involved in improving the environment.

Noise and Vibration emissions caused by vessels have several consequences: first, the emissions could lead to crew health disorders; they affect passengers and harbor surrounding resident comfort, as well as the working dynamics of the vessel. For fishing vessels, which are under no regulation in this aspect, several statistical studies are available, which reveal rates up to $70 \%$ of earrelated disorders among the crew. Secondly, known are the problems that some ship owners (national and international) have had due to complaints and reports of the excessive noise generated by the vessels when moor near highly populated areas.

Furthermore, the high level of Underwater Radiated Noise coming from a high rate of sea transport, and the fact that this aspect "has not been controlled", except for special vessels (Fishing Research Vessels- FRV), were revealed as the main causes of marine life and dynamic alteration, with its ecological and economic consequences for the marine environment and the coast line. It is experimentally verified that fish escape from these areas because of higher rates of underwaterradiated noise as a result of increased sea transport.

It is important to highlight that the most recent regulations/directives, as well as those pending warn and obligate ship owners and vessel operating companies to adopt all the possible measures that would guarantee worker health in relation to Vibration and Noise and in agreement with the new security and health rules. This has resulted in the incorporation of all these new environmental requirements in all the Contractual Specifications of the new shipbuilding practices.

In view of this new and restrictive Environmental Regulatory Framework, supposed to have an impact on the design of the new vessels and, consequently, on production costs, it is evident that Shipbuilding as a globalized industry has now a serious dilemma: it can either "look the other way" or "respond efficiently" to this newthreat, turning (what most would consider "a problem") into a "business opportunity "as long as we can "create an added value strategy". For those shipyards that will choose to "respond efficiently", they now face a "new specialized niche in the market" as a difference against their competitors.

In this work, after a detailed revision of the Current Regulatory Framework and the one about to be enacted (that will affect design and costs), we present Study Case of the results obtained as clear evidence of the correct training and preparation of the Spanish Marine Sector to address these new challenges.

\section{New Regulatory Framework: Current and Future Community Requirements and Directives}

This section aims to offer readers a summarized version of the Current and Future Regulations, with the clear target of raising awareness and approach to the resulting design and production costs. Besides the final price that will be defined according to market requirements and strategies, the author, based on his vast experience in this sector, considers that this knowledge will help readers to have a "more realistic" approach to the "extra costs" that will be assumed when signing a Specification where these new and demanding requirements appear. 
Noise and Vibration Requirements Justification

In 1996, within the Fifth Community Program about environment, "Towards a sustainable development", the European Union proposed, through the Green Paper on Future Noise Policy, [1] that the community strategy about acoustic pollution will be extended, reducing the origin emissions, developing information exchange, and reinforcing programs fighting against noise. In relation to these, on 22 June 2002, Directive 2002/49/CE [2] about the evaluation and management of environmental noise was passed. The main target of this Directive is to define a common approach for all the European Union countries with the aim of avoiding, preventing, and reducing the side effects of ambient noise exposure.

The vessels, as means of transport, generate noise and vibration and will be immediately affected in the Green Policy Framework, due to the "environmental impact reduction". This change will carry an ecological transformation in sea transport and, consequently, in the design of new vessels.

The growing concern in the European Union about improving occupational health conditions of sea workers, as well as reducing the environmental impact in the harbor area and improving marine environmental conditions have resulted in the promulgation of Rules, Policies, and Directives coming from maritime and labor organizations (International Maritime Organization (IMO), International Labor Organization (ILO)). Classification Societies (Bureau Veritas (BV), Det Norske Veritas (DNV), Lloyd Register (LR), Germanischer Lloyd (GL), and Registro Italiano Navale (RINA)), the International Organization for Standardization (ISO) and the Administrations.

It is expected that future Directives, some already in force such as the ones related to "vessel impact in harbors and waterways", and those referring to vessel impact reduction in the marine environment - Underwater Radiated Noise (some Classification Societies have advanced a Notation Class in this aspect), will end up affecting, in an immediate way, the Contractual Specification Framework.

It is important to remark that in some $R \& D$ European Projects within the $7^{\text {th }}$ Framework Program (in which the author is participating) like "SILENV" and "BESST", a future "Green Label" for all types of vessels is being debated.

To help readers to recognize in advance the "technical and economic implications" in vessel design and price, Fig. 1 summarizes Regulations, Polices and Directives in force and the future ones that will appear as Notations Class.

This overview will be done separately by describing the different aspects: Noise and Vibration on board, Noise Radiated to Harbor, and Underwater Radiated Noise, that constitute what the author has called N\&V Full Signature. For a detailed analysis see Ref [3].

\section{Rules and Regulations referring to Vessel Underwater Radiated Noise}

Taking into account that for civilian Shipbuilding, Noise Radiated to Water can be one of the novel aspects, we considered it interesting to extend the chronological aspects of the emergence of new Regulations that will affect it.

The absence of environmental requirements about Underwater Radiated Noise has been a general practice in almost all Contractual Specifications until now, with the only exception of the most modern FRV.

Underwater Radiated problems and their marine environmental impact have only been evaluated in recent years, mainly at the regional level and in those areas where especially vulnerable species live or where more marine mammals and fish are. Glacier Bay (Alaska) deserves special attention; under strict governmental control, vessels are required, as a main requisite, to have the $\mathrm{N} \& \mathrm{~V}$ Full Signature" so as to place them at a proper distance to reduce the impact on the marine life to the minimum. 
Fig. 1. N\&V Full Signature. The Regulatory Framework

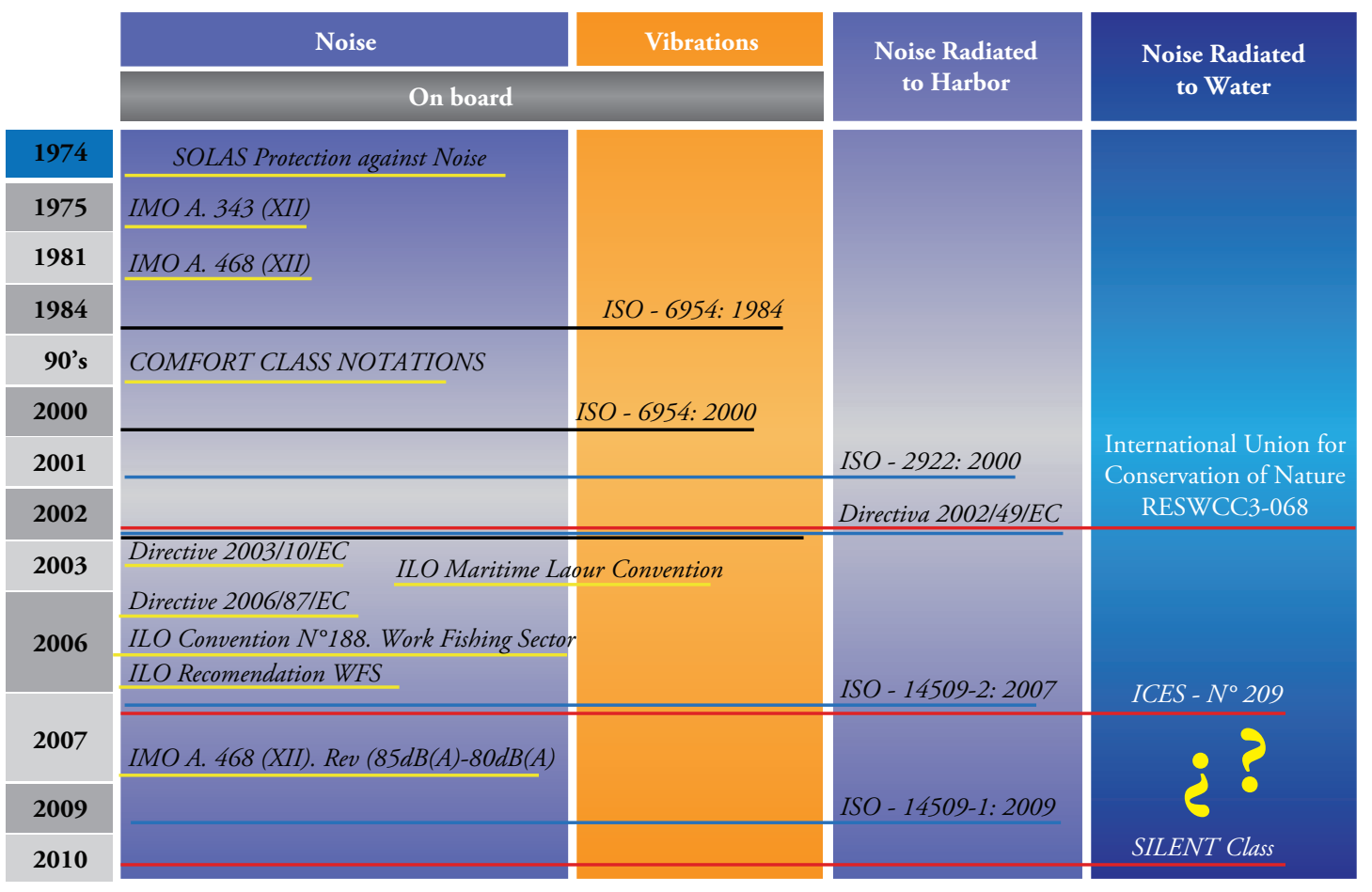

Throughout these years, the emergence of associations to protect marine mammals at international, national, and regional levels has helped in the development of certain rules and treaties that talk about Underwater Radiated Noise and its potential adverse effect on marinelife. Among these associations, it is important to highlight the Internal Union for the Conservation of Nature (IUCN) whose RESWC3-.068 resolution was the first in treating underwater radiated problems, or the International Council for the Exploration of the Sea (ICES) whose ICES-Na209 [7] requirement limits, to a certain extent, the level of Underwater Radiated Noise to a meter from the vessel side and that appears in the most modern fishing research vessel specifications.

The recent Framework Directive 2008/56/ CE about the strategy of reducing the impact on the marine environment, which represents the first international legal instrument including underwater noise from human source explicitly defined as pollution, along with the most recent publication of an Underwater Radiated Noise Measurement Procedure by the Acoustical Society of America (ASA-URN)[8] are the first pillars upon which rules and regulations will set the preliminary steps: technological and design changes that permit reducing or controlling the environmental impact of vessels on marine life.

Classification Societies also deserve special attention; in January 2010, the "SILENT Class Notation" [9] of the DNV addressed to all types of vessels was published, including oceanographic research vessels whose limits are the same as those established by the ICES $\mathbf{n}^{\mathbf{a} 209}$, and set different limits for each type of vessel. This Class Notation advances a measurement parameter procedure for underwater radiated noise.

The authors, based on our experience in the dynamic acoustic design, building and delivery of the most modern Spanish Oceanographic research vessels being used in two R\&D European projects as "technological reference" on what we should do to minimize the impact of vessels on marine life, want to make clear that both vessels are nowadays working in defining the "technological changes" that will be needed in future vessels to be able to accomplish or come close to having the "Green Label" that will include the limits for each Acoustic 
Complete Signature for every kind of vessel: Noise and Vibration on board, Harbor Radiated Noise, and Underwater Radiated Noise.

How will this affect the New Regulatory Framework in the vessel design? Advantages and disadvantages. Threats and Opportunities

In view of this New Regulatory Framework, there are two alternatives, as pointed out in the introduction: to "look the other way" and be limited to a "sub-standard market" or to "answer efficiently" turning what looks like a problem into a business opportunity, this one will give us a favorable position in a more selective market niche, where minimizing the environmental impact of future vessels will be a clear indicator of our difference against cheaper competitors.

Moreover, recent experiences taken from the Spanish Oceanographic Research vessels [10, 11, 12,13 , and 14] that were delivered fulfilling all the current demanding requirements, and based on the confidence given by institutions like the National Industry and the General Secretariat of Marine Affairs and the Spanish Oceanographic Institute let us see a promising and optimistic immediate future.

The following paragraphs will help us understand where we are and where we should go in the design of future vessels, improving certain unattended aspects. In this exam we will explain each part of what we call N\&V Full Signature: Noise and Vibration on Board, Noise Radiated to Harbor and Underwater Radiated Noise, showing for each case a summarized "practical guide".

\section{The "Noise and Vibration Integrated} Management", in all the detailed aspects in other publications [10,11,12, 13, and 14] designed by the author and whose efficiency was proved in strict accomplishment of the most demanding requirements of Oceanographic Research vessels, has been revealed as an "efficient tool" that, when correctly applied, can permit reaching all the new requirements included in the current and new regulations and directives.
The following paragraphs will explain all the recommended "design changes":

- Vibrations and Noise on board. Most shipyards already know the implications in the design of the new requirements. Among others, and due to the increasingly demanding trend in the relative limits, we can highlight the following: 1) Main noise and vibration sources will have to go assembled on elastic mountings correctly calculated, 2) The propeller has to be designed in a way that will not present any cavitation in any of the operational vessel conditions and that the pressure pulses inducted by it will have to be qualified as very low. Also, cavitation and pressure pulse trials will be stipulated. 3) In insulation projects (apart from rock wool and drill galvanized sheet for the machinery areas) materials to reduce or minimize "structural noise" transmission such as viscoelastic with tiles will also be considered. The weight incidence of these materials will have to be taken in account. The accurate selection of these materials with the attenuation data required and their assembling could be critical. 4) Elastic support in the exhaust ducts and insulating elements in the pipes will also have to be considered. 5) The HVAC system will have to be received "on site" to guarantee that noise levels that HVAC introduces in each compartment are $5 \mathrm{~dB}(\mathrm{~A})$ under the noise limit of each place. 6) In the design phase, silencers will have to be installed for the MMEE and AAEE exhaust, as well as for the inlets/outlets of the fans on the decks or open areas. 7) The compartment will be "floating type" with no rigid connections to the vessel structure. 8) Providers will be chosen in relation to their "contractual commitment with the shipyard" about the requirements that the specification has requested, as well as with their ability to "provide reliable dynamic-acoustic data" of their supply. The shipyard must know and evaluate the absence of this information that will result in an increase in their expenses. 9) Vibration Prediction to guarantee that the vessel structure does not show any resonance risk and Noise Prediction to optimize and 
estimate the insulation correctly will have to be contemplated.

- Noise radiated to the Harbor. This recent requirement implies the following specifications: 1) Special attention will have to be paid to the correct estimation and design of the noiseless acoustics of the inlets/outlets of the fans in the shipside and also to the MMEE and AAEE exhaust. 2) Special acoustic treatments will have to be plan for the ventilation ducts, whose engines should be assembled on an elastic mounting correctly calculated. 3) The shipyard will have to ensure the "contractual commitment" of these suppliers with the dynamic-acoustic objectives, and if necessary, will ask for Factory Acceptance Tests. 4) A calculation tool will have to be used to allow us to make a Prediction of Noise Radiated to the Harbor during the project stage.

- Underwater Radiated Noise. Contrary to previous cases, only those national shipyards involved in the building of Oceanographic Vessels know the design implications stemming from the Underwater Radiated Noise requirements. It is clear that the scope of these design modifications to fulfill these requirements will depend on the limits that will be finally decided as "threshold" to avoid affecting marine life. A detailed description of the current strictest requirement could be found in the References [11, 12, and 13]. As a summary, we can highlight the following: 1) All previous detailed aspects will be applied. 2) The propulsion will have to be Diesel-Electric with direct current main engines. 3) DieselGenerator groups will have to go on double elastic mountings previously calculated and with a contrasted efficiency through a factory acceptance test. 4) The propeller, apart from fulfilling all previous requirements, will have to be a fixed blade. 5) All types of propulsion reducers must be avoided. 6) Special coatings, like viscoelastic with tiles, must be applied in submerged hull areas near the engine rooms. 7) A special calculation tool that will help us to Predict Underwater Radiated Noise during the project stage must be used, with the intention of introducing any types of changes on time. It must be known that, in general, in case of "non-fulfillmentfulfillment" there is no way back, as corrections tend to be extremely expensive.

After briefly reviewing the necessary "potential design modifications" that will be needed to obtain vessels that comply with the most recent and newcoming Regulations and Directives, the next step will be to inform "in advance" all the professionals involved in the Specifications signing about them. It is of paramount importance that these professionals have a deep and extensive knowledge of the implications that these modifications will have, in order to "enhance their value" while negotiating the vessel's price..

\section{Case Study: Ro-Ro Navantia Vessels for ACCIONA TRANSMEDITERRÁNEA}

\section{Description and Main Particulars}

At the end of March and during mid August 2010, NAVANTIA-Factoría de Puerto Real delivered the RO-RO vessels "José María Entrecanales" (C-509) and "Super-Fast Baleares" (C510) to the Spanish company ACCIONA TRANSMEDITERRÁNEA. Both last generation units constitute the biggest freighters in the Spanish market. They have been designed to have two weekly rotations in routes between 700 and 800 nautical miles or, alternatively, a weekly rotation in routes of 1.500 nautical miles. The main characteristics of these vessels and their main machinery are collected in Fig. 2.

Finally, as important noise sources in these types of vessels, we can highlight the ventilation of the hold and the engine room. Both vessels have 58 ventilation units, some of them with a capacity of up to $120,000 \mathrm{~m} 3 / \mathrm{h}$.

Basic Objectives of the Project. Noise and Vibration Specifications. ISO Standard 2992/2000

In the contractual specification signed by the shipyard and the ship owner, a "Noise and 
Fig. 2. Main characteristics of the vessels and their main machinery

\begin{tabular}{|c|c|}
\hline \multicolumn{2}{|c|}{ Main Particulars } \\
\hline Total Lenght & $209,00 \mathrm{~m}$. \\
\hline Lenght b. PP & $190,00 \mathrm{~m}$. \\
\hline Breadth & $26,5 \mathrm{~m}$. \\
\hline Depth to M. Deck & $9,60 \mathrm{~m}$. \\
\hline Design Draught & $7,00 \mathrm{~m}$. \\
\hline Molded Draught & $7,10 \mathrm{~m}$. \\
\hline Dead Weight & $9,325 \mathrm{t}$. \\
\hline Potencia Propulsora & $\begin{array}{l}4 \times 10,800 \mathrm{~kW} \text { a } 500 \\
\mathrm{RPM}\end{array}$ \\
\hline Speed & 26 Knots \\
\hline Autonomía & \\
\hline $\begin{array}{l}\text { Capacidad de Carga: } \\
\text { - } \quad \mathrm{N}^{\circ} \text { of modules } 14,3 \mathrm{~m} . \\
\text { - } \quad \mathrm{N}^{\circ} \text { Containers "mafi" } \\
\text { - } \quad \mathrm{N}^{\circ} \text { Cars at Deck }\end{array}$ & $\begin{array}{l}187 \\
23 \\
100\end{array}$ \\
\hline Crew & 40 Persons \\
\hline Classification & BUREAU VERITAS. \\
\hline
\end{tabular}

\begin{tabular}{|c|c|}
\hline \multicolumn{2}{|c|}{ Main Particulars of Main Machinery } \\
\hline \multicolumn{2}{|c|}{ Main Diesel Engines } \\
\hline Mark & $\begin{array}{l}\text { MAN DIESEL } \\
\& \text { TURBO }\end{array}$ \\
\hline Model & 9L 48-60 B. \\
\hline Nominal Power & $10,800 \mathrm{~kW}$ \\
\hline Nominal Speed & $500 \mathrm{RPM}$ \\
\hline Number of Cylinders & 9 \\
\hline $\mathrm{N}^{\circ}$ of stroke & $4 \mathrm{~T}$ \\
\hline $\mathrm{N}^{\circ}$ de Units & 4 \\
\hline \multicolumn{2}{|c|}{ Gear Box } \\
\hline Mark & RENK \\
\hline Reduction Rate & 3,324:1 \\
\hline $\mathrm{N}^{\circ}$ de Units & 2 \\
\hline \multicolumn{2}{|c|}{ Propeller } \\
\hline Diameter & $5,200 \mathrm{~mm}$ \\
\hline Number of Blades & 4 \\
\hline Pitch & Variable \\
\hline Nominal Speed & 150 RPM \\
\hline
\end{tabular}

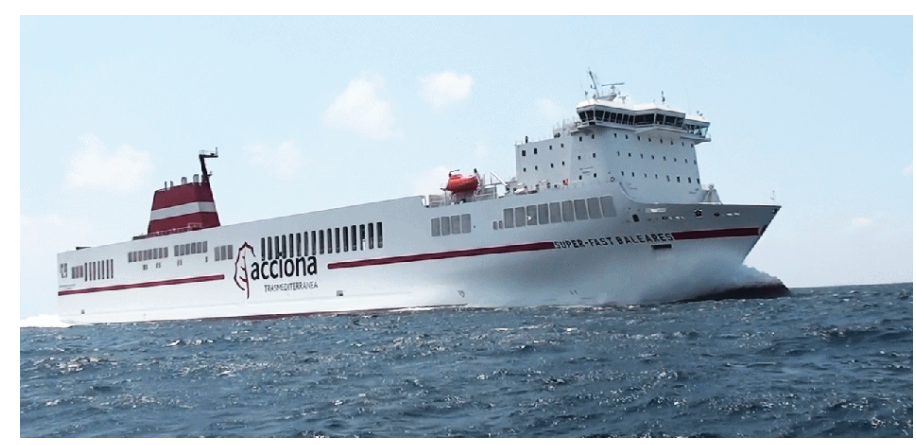

Vibration Level" specific section is highlighted and because of its importance for this project, it is shown in these different sections: 1) "A Noise Prediction will be performed in different areas of the vessels". 2) "The acceptable Noise levels will be those established by the IMO in the A.468 (XII) Resolution [4]". 3) "A noise level measurement will be done in the places and conditions established by the IMO to prove that they do not exceed the limits". 4) "Vibration levels in the cabin, common areas, and public areas for crew and passengers will not be in the zone of "values likely to adverse comments", established by the ISO Standard 6954/2000 [5]". 5)"Exterior noise levels under $80 \mathrm{~dB}$ (A), measured according to ISO 2922/2000 [6] with the vessel in operational conditions in the harbor". 6) "A vibration measurement will be carried out to check that the vessels fulfill the previously mentioned rule".

Noise and Vibration requirements were set thus: 
Vibrations in compliance with ISO Standard $\mathbf{6 9 5 4 / 2 0 0 0 ~ [ 5 ] . ~ N o i s e ~ c o r r e s p o n d s ~ t o ~ I M O ~ A . 4 6 8 ~}$ (XII) Regulation [4].

The following comments and observations are taken from a Noise and Vibration section included by the ship owner in the Contractual Specification:

- It is the first time that a fulfillmentfulfillment requirement about noise level (80 $\mathbf{d B}(\mathbf{A}))$ with the vessel in operational conditions in the harbor appears in the Contractual Specification. This is considered a clear example of foresight of the evolution in Environmental Regulations from the Ship owner's side.

- The ship owners "show a high sensitivity" to the working conditions of their employees (the crew) and the clients (the passengers), demanding the fulfillment of noise and vibration limits set by current rules IMO A.468 (XII) Regulation [4] and ISO Standard 6954/2000 [5].

- Finally, and to be sure that all the appropriate measures will be considered by the shipyard, the ship owner demands compulsory "Prediction Studies".

Normally, the first position to take is to continue "doing things as they were done for the last years", without taking any preventive measure that can guarantee the compliance with the rules. This position, even when believed to "reduce cost", only leads to the opposite effect: several penalties, last minute corrections with fines for late delivery, and excessive costs in the corrections, as well as vessels already finished and it is technically and economically impossible to be modified.

In the past, when these specifications where ambiguously defined, it was more frequent to "toss the coin" and wait for the vessel to vibrate or not, it could be normal at that time given the state-ofthe-art in these matters. Nowadays, as it can be proved, it makes no sense and has no technical or economic justification. In fact, in the case study that will be presented in this work, it will be clear that not taking preventive measures regarding noise radiated to the harbor, could have led to a brand new vessel with limitations in the loading and unloading operations in certain Spanish and
European harbors, and also to possible fines and complaints.

Before, with other less strict specifications on noise and vibration it was not necessary to have profound knowledge in this area and it was possible to avoid complications in the compliance. But currently, it will be increasingly obvious that those responsible for signing the specifications will need to have some basic knowledge or experience on this matter, or that they will receive professional advice to quantify the real economic incidence in the final price.

Going back to our case, if the studies required by the shipyard had not been done, the vessels involved in this project would not have accomplished the contractual specification, mainly in relation to Noise Radiated to the harbor.

The requirement from the ship owner to fulfill the ISO 2922 Standard "Measurement of airborne sound emitted by vessels on inland waterways and harbors" [6], requiring a contractual limit of $80 \mathbf{d B}$ (A) at 25 meters from the vessel. The rule has as a main goal of avoiding complaints and fines when the vessel ties up near densely populated areas.

The shipyard (NAVANTIA-Puerto Real) and the engineering company (SENER), looking at the recommendations made by the authors of this material, addressed this requisite even more realistically than required by the specification, by asking for noise radiated prediction studies that allowed satisfying not only the ship owner's requirements, but also to have an almost unique reference of a "Silent Vessel" in the harbor.

\section{Shipyard response: What has been done? How has it been done?}

\section{General information}

First, the ship owner ACCIONATRANSMEDITERRÁNEA, based on their previous experience and aware of the importance of fulfilling noise and vibration aspects, required 
the use of Noise and Vibration Simulation and Prediction techniques as a guarantee to meet those goals.

Meanwhile, the shipyard, NAVANTIA-Puerto Real, with vast experience in the noise and vibration field, with civilian and military cargo vessels, in an attempt to meet all the strict requirements, showed from the beginning special attention to covering all the ship owner's requests; knowing that to fulfill the demanding specifications it was necessary to understand the principle that "Dynamic and acoustic design of the vessel is most important" in this project.

Consequently, NAVANTIA-Puerto Real required SENER and the assistance of a specialized company (TSI), which was in charge of Noise and Vibration Integrated Management and added the "design principle" to all its processes.

\section{What has been done? Basic principles}

Vessels are elastic systems that when under periodic forces, coming from different sources, are "subject to vibrations". The vibration level obtained in the system (vessel) depends, mainly, on three parameters: 1) The Intensity or magnitude of the excitation forces. 2) The Rigidity of the structure. 3) The dynamic Amplification at different frequencies due to local and global resonance phenomena.

Thereby, the possible actions to keep vibration levels under the pre-set limits are the following: A) Minimize the excitation forces of the system. B) Avoid flexible structures from a dynamic point of view. C) Avoid resonance phenomena by coincidence of structural frequencies and excitation frequencies.

Similarly, and from an acoustic point of view, the vessel has built-in Sonorous Focus: Main engine and Auxiliary ones, Propeller, Hydraulic Systems, HVAC, etc. that are airborne and structure borne noise generators, noise transmitted or spread along the structure of the vessel (Means) that reaches the different premises (Receivers), as well as radiated to the water.
Likewise, the possible actions to maintain noise levels under the pre-set limits are the following: 1) Minimize the resonant and vibration power from different resonant focuses. 2) Reduce or diminish their transmission to the medium. 3) Duly isolate the receptors.

\section{How has it been done? Procedures}

If we review the possible actions to control noise and vibrations levels in the vessel, we confirm that they can be grouped into two modules:

- A first module, comprising all those actions aimed at minimizing the magnitude of the excitations (noise and vibration) generated by different sources and focus, which are completely beyond the shipyard's duties and competence, and which correspond to the different suppliers' scopes.

- A second module that includes all the possible actions related to vessel structure, absence of resonance phenomena, separation and isolation of receptors and focus, correct assemblies and isolation are within the aspects of the Project, Structure and General Disposition, Building and Assembly, and in consequence, embraces to the shipyard's scope.

The first module within the Noise and Vibration Integrated Management and as a control mechanism should incorporate "dynamics and acoustics specific requirements" in the purchase specifications of the different supplies, as well as Reception and Verification Procedures.

In the second module of possible actions, under the direct responsibility of the shipyard, the previously mentioned principle "Dynamics and Acoustics Vessel Design is most important" is assumed from the beginning of the project. This implies the following points: A) Name an internal and external coordinator that will supervise and coordinate, from a dynamic-acoustic point of view, all the processes and supplies. B) The project must consider the selection of shapes and wakes that minimize the risk of propeller cavitation, as well as careful maintenance of the structural continuities. C) The General Disposition must guarantee an optimum separation between focus and receptors 
with high acoustic requirement, along with minimum isolation levels. D) Assemblies must minimize the "building" of noise and vibration transmission bridges to avoid connecting rigidly moveable parts of the equipment to hard points of the vessel structure.

To supplement, and for the purpose of minimizing resonance risk and optimizing the acoustic behavior of the vessel, the Noise and Vibration Integrated Management considers carrying out a Dynamic Acoustic Design of the vessel that will be accomplished in the following sections: 1) Vibration Prediction. 2) Noise Prediction. 3) Radiated Noise Prediction.

Experience shows and the case study presented in this document reinforces this, that the proper introduction of this Noise and Vibration Integrated Management methodology [11, 12, 13] yields, among others, the following advantages: V1) Ensure that all the preventive measures were taken in the different processes and in the right moments. V2) Incorporate this methodology to future manufacturing standards. V3) Fulfill the specification, and finally, "Client-Shipyard" satisfaction at the lowest possible cost.

Practical application of the "NOISE AND VIBRATION INTEGRATED MANAGEMENT" in the vessels: "JOSÉ MARÍA ENTRECANALES" and "SUPER-FAST BALEARES".-

\section{General Scope}

The experience based on the excellent results obtained in the "Silent Vessels": Oceanographic Vessels "Miguel Oliver", "Sarmiento de Gamboa", and the Fishing Research Vessel "Emma Bardan", permits confirming that compliance of these strict requirements demands a complete development of the methodology of Total Noise and Vibration Management that the authors are applying and that includes, in a minimum range, the development of the principle and procedure previously exposed.
With this "first activity level", it sought for the shipyard to develop and exert "control" over those aspects that, as previously described, are in the scope of the suppliers. The intention with this is to achieve what is called "contractual sensitivity" of the suppliers towards the dynamic and acoustic objectives of the project. Its "no-application", leaves the shipyard, in many occasions, "with tight hands" when it comes to finding more economic and technically efficient solutions or countermeasures.

The "second level" of activities considers all those aspects in direct competence with the shipyard, as it is the supplying of a structure with an appropriate dynamic design: without resonance and enough acoustic isolation to guarantee the minimum requirements. In this section, all the simulation techniques are integrated, like: A) Vibration Prediction through Finite Element Method. B) Noise level Prediction in the vessel locals through SEA Method. C) Noise Radiated to Harbor prediction, when required. D) Underwater Radiated Noise Prediction, when required.

In the case study we are working on, the development of the Noise and Vibration Integrated Management scope has been, as indicated, "partially" focusing only and exclusively on the application of "Simulation Techniques" for those aspects required in the specification: Vibrations, Noise and Noise Radiated to Harbor.

Prediction through Finite Element Method in the building of NAVANTIA-Puerto Real C-509 and C-510

A finite-element mathematical model of calculation (FEM) was applied, seeking to avoid dynamic amplification phenomena due to possible "Resonance Phenomena" in the vessel structure, to identify own frequencies and avoid their coincidence with the main excitation sources of the vessel: Forces and Moments of Main Engines excitation and Forces coming from Pressure Pulses inducted by the propeller on the sternpost.

The application, to this dynamic model of the vessel structure, of the different forces of the excitation 
source: Main Engines and Propellers, will help us to obtain the "Expected Vibration Levels" in the different areas throughout the vessel structure. From the comparison between these "Expected Vibration Levels" with the limits required in the ISO Standard 6954/2000 [5] demanded in the specification, decisions will be taken that will allow us to validate the structure from a dynamic behavior point of view or introduce those structural modifications that guarantee this compliance within the required limits. In Fig. 3 we can see a summary of the methodology applied.

\section{Description of the Mathematical calculation model.}

To represent the dynamic characteristics (mass and stiffness) of the structure, two-dimensional elements like plate (shell) were mainly applied, capable of admitting distortions in its plane and perpendicular to this, using one-dimensional elements (beam) for the primary structure and struts. Equipment with weight over $1000 \mathrm{~kg}$ has been considered as point masses distributed in the area where beams are supported, with the exception of the main engine and the reduction gear that has been modeled with two-dimensional elements. To perform the calculation, ballast and consumer tank filling were taken into account. In Fig. 4 the mathematical model used can be seen.

\section{Calculation Fulfilled.}

On the mathematical model, two types of

Fig. 3. Methodology of the Vibration Prediction

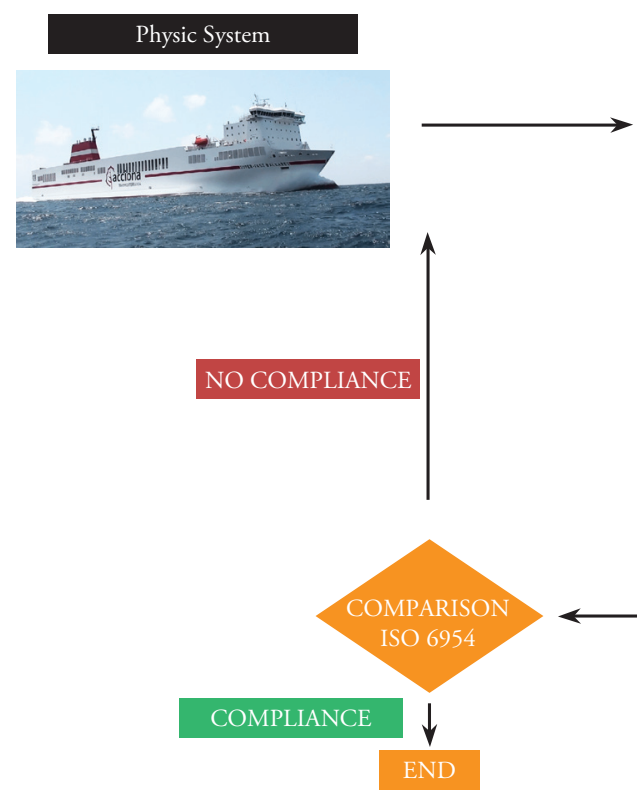

Mathematical Model

$[\mathrm{M}] \cdot \ddot{\mathrm{y}}+[\mathrm{K}] \cdot \mathrm{y}=0$

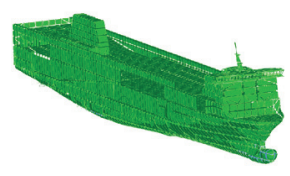

Modal Analysis

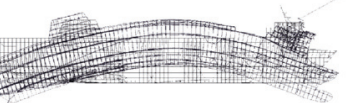

Foced Responce

$[\mathrm{M}] \cdot \ddot{\mathrm{y}}+[\mathrm{C}] \mathrm{y}^{\prime}+[\mathrm{K}] \cdot \mathrm{y}=[\mathrm{F}]$

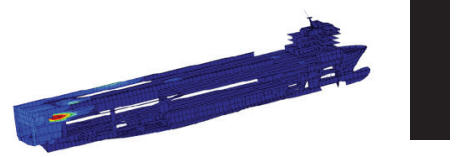

calculations were performed, as described in the following lines:

Modal Calculation: Through this calculation, the eigenfrequencies or resonance frequencies of the vessels and their vibration mode shapes were obtained. The coincidence between eigenfrequencies and excitation frequencies (propellers and propelling engines) can produce a phenomenon called resonance and then high levels of vibration could be produced. This type of calculation is an essential requisite to be able to make the forced response calculation or to predict vibration levels.

Forcedresponse. Vibration levelsprediction: This calculation includes the characteristics of the vessel through the modal calculation and the characteristics of the excitation sources (amplitude and frequency) to obtain the expected vibration levels in the vessel structure.

\section{Results obtained.}

As previously pointed out, the relative location 
Fig. 4. Finite-Element Mathematical Model

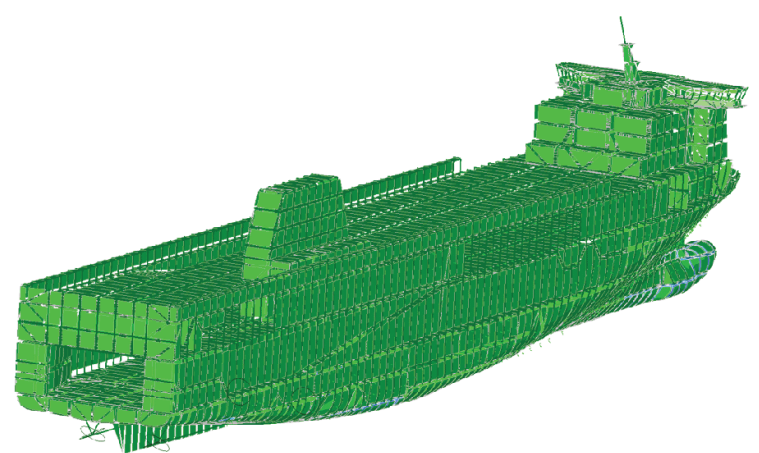

of these eigenfrequencies in relation to excitation frequencies mainly inducted by the main engines and the propeller, allows a first evaluation of "resonance risk" at local and global levels.

In Figs. 5 and 6, vibration modes and shapes associated with the first three modes or eigenfrequencies of the ship-beam obtained, were collected.

For readers who are not experts in this matter, the view of these vibration ways help us understand, in didactic manner, why they are called "Vibration frequencies and shapes of the ship-beam".

Because of the high level of discretization used in which almost all elements were represented, the modal calculation allows us to obtain a high level of local eigenfrequencies, corresponding to deck plates, bulkheads, etc., whose graphical and numerical representation would be thorny. In this case, it was preferred to represent the following step of "Forced Response" that will permit, in a more illustrative way, identifying those structural areas with more problems or risks of "Local resonance".

For the "Forced Response" calculation, the main excitation forces used were: pressure pulses inducted by the propeller in the sternpost to the excitation frequencies 1xBPF (Blade Pass Frequency) and $2 \mathrm{xBPF}$, and the forces and free moments coming from the main engines to the excitation sources 1xRPM, 2xRPM and 4.5 RPM, as harmonic or more significant orders. Auxiliary engines, not considered because of their isolation by elastic suspension and the bow propeller, due to its study can be found within an analysis of noise presented in this work.

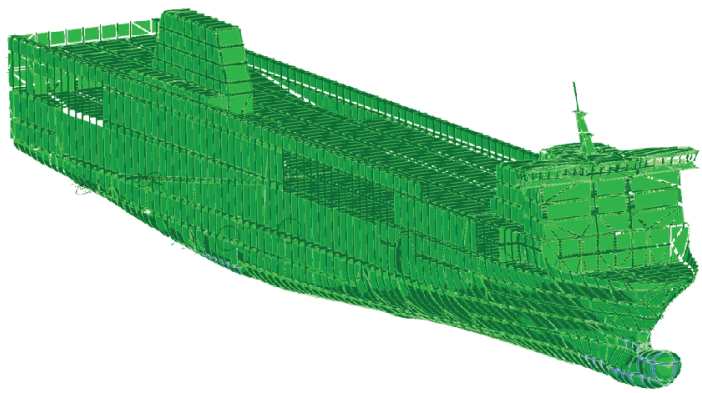

Fig. 5. First Vertical Bending Mode Shape. $1.78 \mathrm{~Hz}$

$$
\begin{aligned}
& \text { Displacement Mag } \\
& \text { Deformed Original Mode } \\
& \text { Max Disp } \bullet 1,0000 \mathrm{E} \bullet 00 \\
& \text { Scale 5,7000E } \bullet 01 \\
& \text { Mode } 8, \bullet 1,7861 \mathrm{E} \bullet 00
\end{aligned}
$$

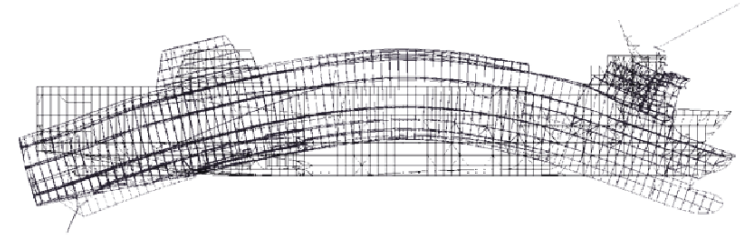

Fig. 6. First Torsional Mode Shape. $2.72 \mathrm{~Hz}$

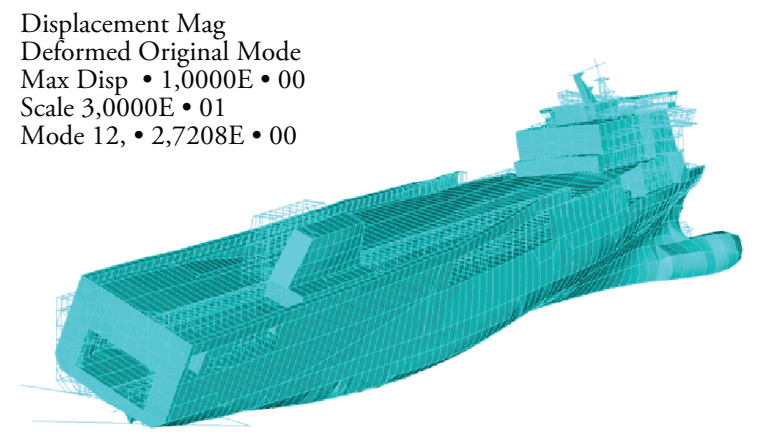

The excitation amplitudes previously mentioned, those corresponding to the propellers and the engines, appear at nominal regime $(150 \mathrm{rpm}$ propeller speed and $500 \mathrm{rpm}$ propelling engine speed). For other working regimes, the excitations have lowered with hydrodynamic laws. It is important to highlight that vibration predictions do not cover the working conditions of the propeller at regimes under nominal, in which propeller cavitation is produced, like in harbor maneuvers and working with the machine back (crash stop). 
The application of these excitation forces, in the most conservative case that both are acting in phase, the mathematical model has helped us to obtain, through colored maps, the distribution of the "expected vibration levels" in the different locations of the vessel structure. In Fig. 7, different colored maps are collected to show the different main excitations.

\section{Noise Prediction through SEA Method}

\section{Brief introduction to SEA Method.}

To make a noise prediction it is necessary to consider the acoustic excitations and their transmission paths, this means working in high frequency. The SEA Method (Statistical Energy Analysis) offers a way to alternatively model FEM and BEM, and to represent the vibratory state of a system. The model represents the means behavior of a group of similar systems and it also includes an uncertainty factor in the model. The vibratory state is expressed in terms of vibratory energy of individual components. The application of these excitations is expressed in terms of power. And the relation between the excitations and the energy of the elements is expressed in terms of energy flow.

\section{General description of Noise Prediction.}

In this chapter the intention is to describe the general methodology for noise level prediction in different locals of the vessel due to the focus of existing noise, using SEA method. The first step to define a noise model is to create the topology of the vessel. Once created, the second step is to create the analysis model. In the analysis model, information about the thickness of the plates, space between stiffeners, noise sources definition, local receptor definition and local transmitting and acoustic treatment applied information must be included. With the analysis model created, we can proceed to solve it and as a result expected noise levels in the selected compartments are obtained.

The comparison of theses expected levels with the established limits in the technical specification, will take us either to finish the process or, in the contrary, through a repetitive process to simulate special systems of isolation aimed at reducing noise levels in those compartments which do not accomplish the Specifications. In Fig. 8 a graphic Flow Diagram that corresponds to this methodology is described.

Fig. 7a. Expected levels in the structure for the main excitations (1xBPF)

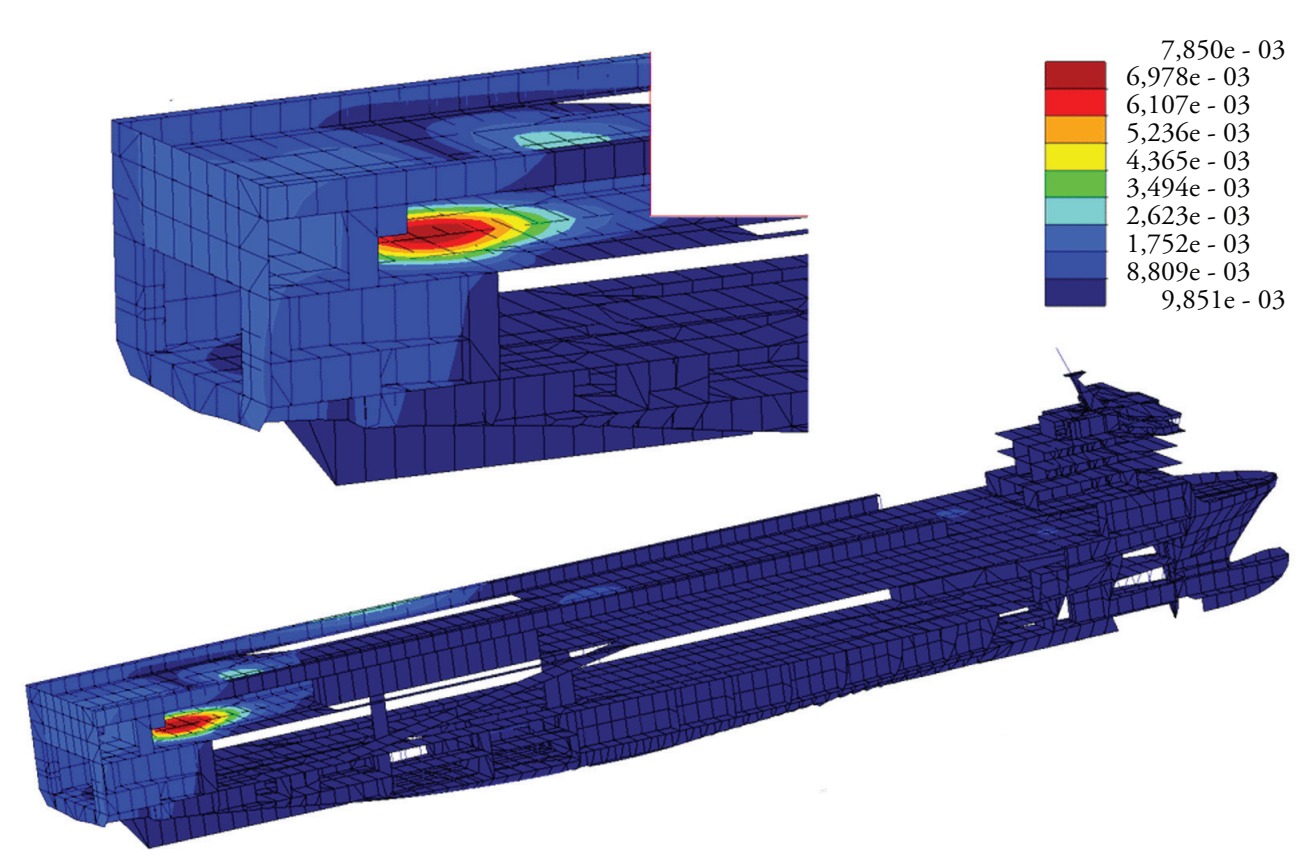


Fig. 7b. Expected levels in the structure for the main excitations $(4,5 x R P M)$

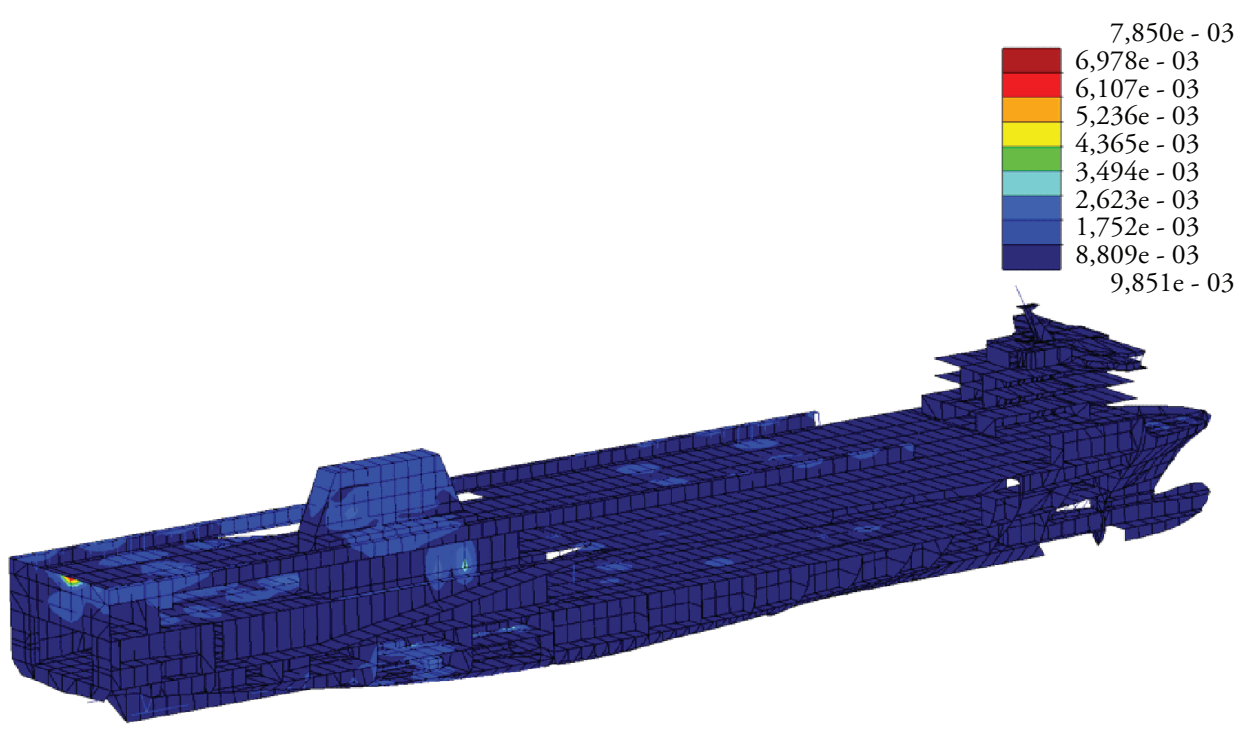

Fig. 8. Methodology of the Noise Prediction

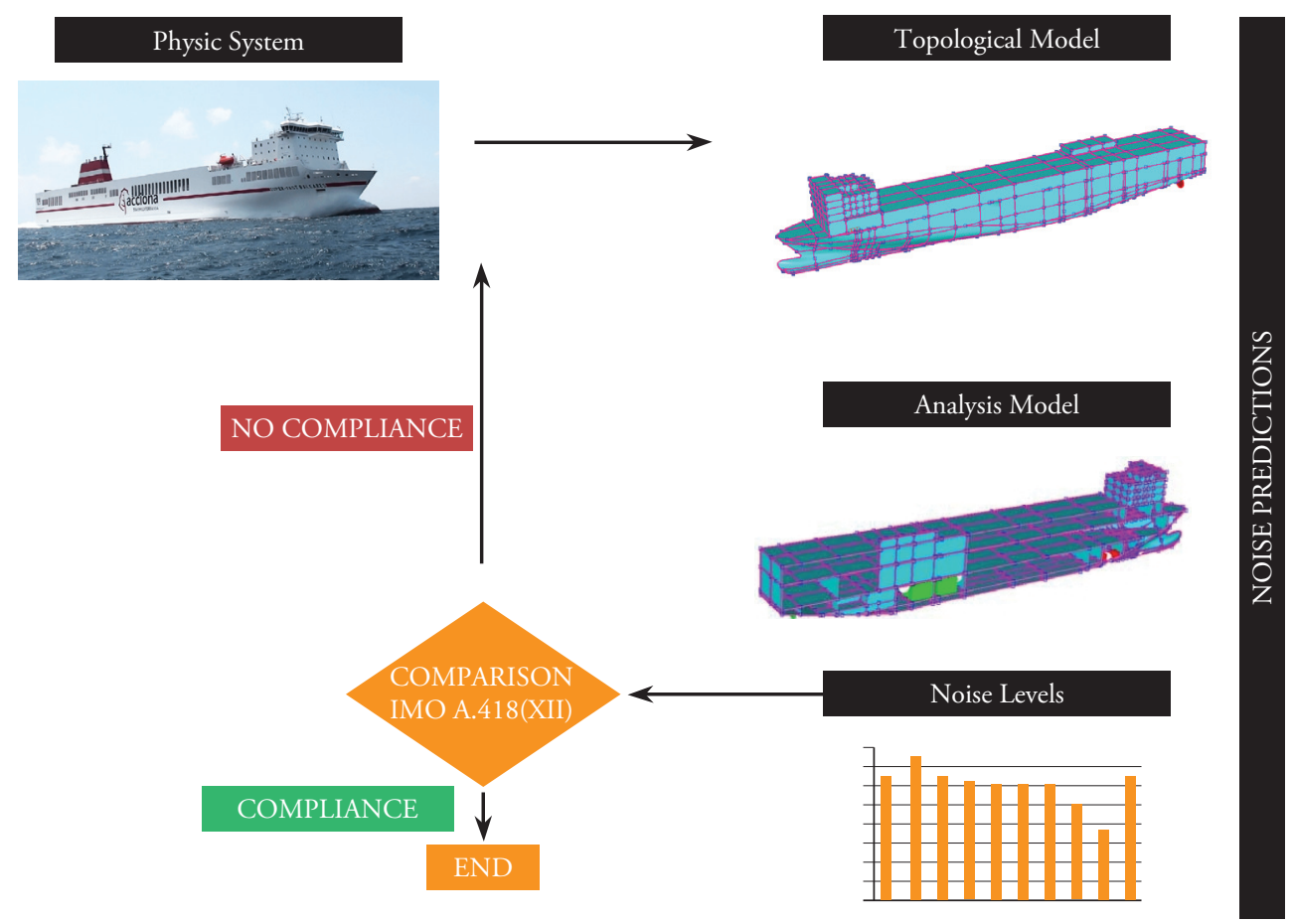

Mathematical Model Description.

SEA method includes two types of existing structure borne noise, the one transmitted by a noise source through the structure, and the one generated in the structure due to airborne noise. To calculate noise level, the following parameters have been taken in account:
1) The thickness of the plates and the distance between the reinforcement. 2) Air noise level and structural noise level of the different equipment. 3) Isolation drawings in bulkheads and roofs, pavement and sub-pavement. 4) Plan of the General Disposition of the vessel and situation of focus and locals. 
The noise sources, among others, that have been considered to predict noise in the C-509 and C-510 are the following ones: propellers, main engines, gearboxes, auxiliary engines, thrusters, compressors, harbour generator, purifiers, steering gear, HVAC units, fans engine room, garages and technical spaces. In Fig. 9 we can see the Acoustic Model used.

Noise Results obtained with the original Model. Analysis and Acoustic reinforcement. Original Model Results/ Modified Model.

Noise level predictions in the locals of the vessel have been done considering the working conditions in Free Sailing at $\mathbf{9 0 \%}$ MCR. Additionally, a prediction of noise level has been done for the Load/Unload condition.

In the following table Fig. 10 shows, for one representative deck, the equivalent pressure levels in $\mathrm{dB}$ (A) obtained in each local through simulation in both analysed conditions. Meanwhile, Comfort level limits established in each local are shown,
Fig. 9. Acoustic Model of the RO-RO's C-509/510

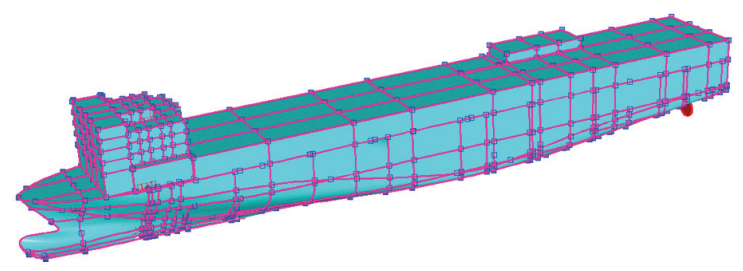

in relation to the Specification, as well as the corresponding prediction evaluation.

UNACCEPTABLE levels are those that exceed the specified limit, SEVERE levels are those at less than $2 \mathrm{~dB}$ (A) below the limited level, and ACCEPTABLE are those at $2 \mathrm{~dB}$ (A) below the specified limit. Additionally, we indicated if this evaluation refers to Free Saling or Load/Unload condition. In Fig. 11 found are the distribution of the expected noise level in C-509/510 with the Original Insulation and the operational conditions tested: Free Sailing 90\% MCR and Load/Unload and the corresponding Modified Acoustic Model.

Fig. 10. Noise Level Prediction in a Representative Deck

\begin{tabular}{|c|c|c|c|c|}
\hline \multicolumn{5}{|c|}{ Deck 7 - Forw-Aft- Sound Pressure Levels Expected } \\
\hline Space & N.L. & L/UNL & Limit & Assesment \\
\hline 23. Chimney & 84 & 80 & 110 & ACCEPTABLE \\
\hline 24. Port Generator & 81 & 77 & 75 & ACCEPTABLE \\
\hline 25. Chimney & 84 & 80 & 110 & ACCEPTABLE \\
\hline 26. Store & 80 & 64 & 90 & ACCEPTABLE \\
\hline 27. Comedor Tripulación & 59 & 64 & 65 & SEVERE \\
\hline 28. Passenger Cabin & 61 & 67 & 60 & OVER LIMITS \\
\hline 29. Passenger Cabin & 61 & 67 & 60 & OVER LIMITS \\
\hline 30. Passenger Cabin & 61 & 67 & 60 & OVER LIMITS \\
\hline 31. Passenger Cabin & 61 & 67 & 60 & OVER LIMITS \\
\hline 32. Passenger Cabin & 62 & 68 & 60 & OVER LIMITS \\
\hline 33. Passenger Cabin & 62 & 68 & 60 & OVER LIMITS \\
\hline 34. Comedor pasajeros & 62 & 68 & 65 & OVER LIMITS \\
\hline 35. Kitchen & 57 & 62 & 75 & ACCEPTABLE \\
\hline 36. Gambuza seca & 57 & 62 & 75 & ACCEPTABLE \\
\hline 37. Clothing and Laundry & 63 & 69 & 75 & ACCEPTABLE \\
\hline 38. Officer's mess & 62 & 68 & 65 & OVER LIMITS \\
\hline
\end{tabular}



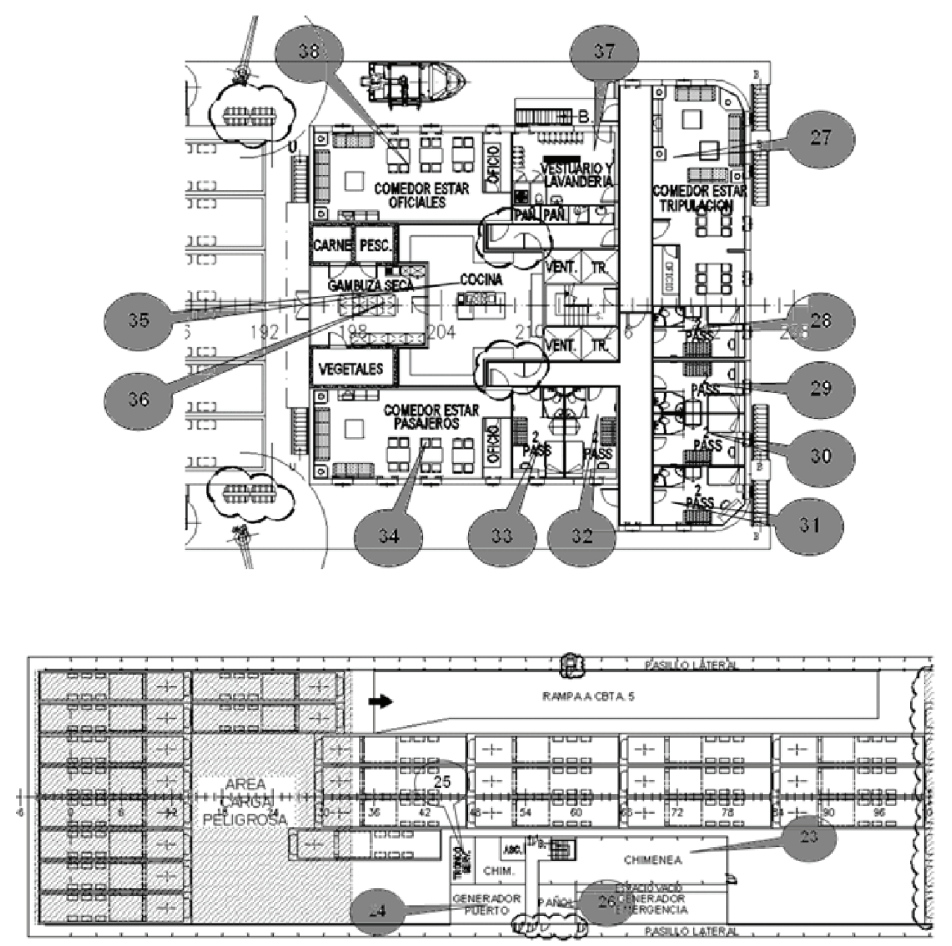

Fig. 11a. C-509/510. Noise Level Distribution. Original Insulation

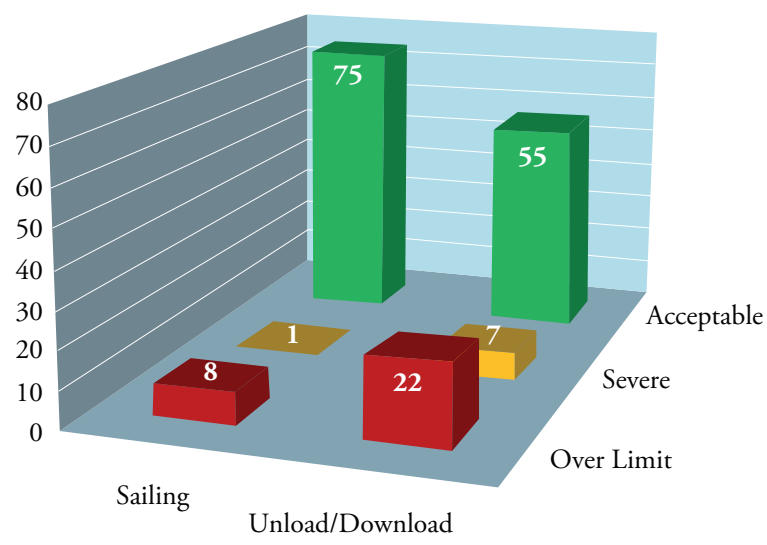

Noise Radiated to Harbour Prediction. Answer to the new requirements

\section{Introduction.}

The appearance of a "totally new requirement" in the Specification of C-509/510 of NAVANTIA-Puerto Real from ACCIONA TRANSMEDITERRÁNEA, that the "Exterior noise level should be under $80 \mathrm{~dB}(\mathrm{~A})$, measured according to ISO 2922/2000 [6] with the vessel
Fig. 11b. C-509/510. Noise Level Distribution. Modified Insulation

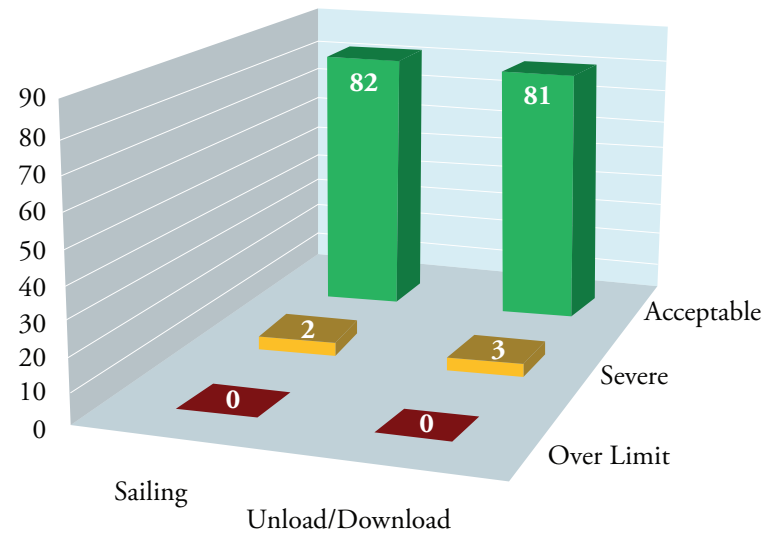

in operational harbour condition", has constituted a "novelty".

The reasons for this "new requirement" are two: one is the Operational, that answers the need of the Ship-owner to avoid complaints and fines. The second is the Vision and Sensitivity from ACCIONA TRANSMEDITERRÁNEA in accomplishing the Community Directives related to Evaluation and Management of Ambient Noise 
in the Harbours, Directive 2002/49/CE [2] specifically.

In this point we need to ask ourselves "What did the shipyard do in view of these new requirements?", "Did the shipyard know about the technical and economic incidence of this "added value" that the vessel required?".

\section{Calculation Method applied.}

The prediction of the noise generated by the vessel to the harbour has been done counting as a main noise sources the inlets/outlets of the ventilation system that the vessel can have in use during the stay and operations in the harbour.

Those inlets/outlets of ventilations had been considered as hemispherical noise sources, in a way that each one generates a sound field of spherical waves. The levels of acoustic power, from each inlets/outlets, have been calculated considering the power and noise pressure of each fan, the ducts dimension and the fan chamber, and its acoustic insulation in case of having it.

As a consequence the accuracy of the obtained results has been constrained by the precision of the data given by the supplier. As a result, with the experience of the authors, this data had to be experimentally proved through factory acceptance tests. In this vessel, the main noise sources of Harbour Radiated Noise are integrated by 58 Ventilation fans from the garages and machinery rooms.

The exhaustion of the main engines and the auxiliary ones have not been considered in this analysis, as the acoustic treatment of this noise source is constrained by the fulfillment of the noise limit in the exterior decks.

With these noise sources characterized, and using the Calculation Model described in Fig. 12 and with the tool developed with TSI, called "NoRaPort", we proceeded to estimate, for the different configurations, noise level at the different distances of the vessel. Not only in the quay but also in the main sections of it, where most of the noise sources to the harbour were found. The comparison of these "expected noise levels" at different distances and mainly at $25 \mathrm{~m}$ of each side of the vessel, and the comparison of the Specified limit of $80 \mathrm{~dB}(\mathrm{~A})$, allowed us to optimize the acoustic design of the different ventilation systems.

Fig. 12. Noise Radiated to the Harbour Model

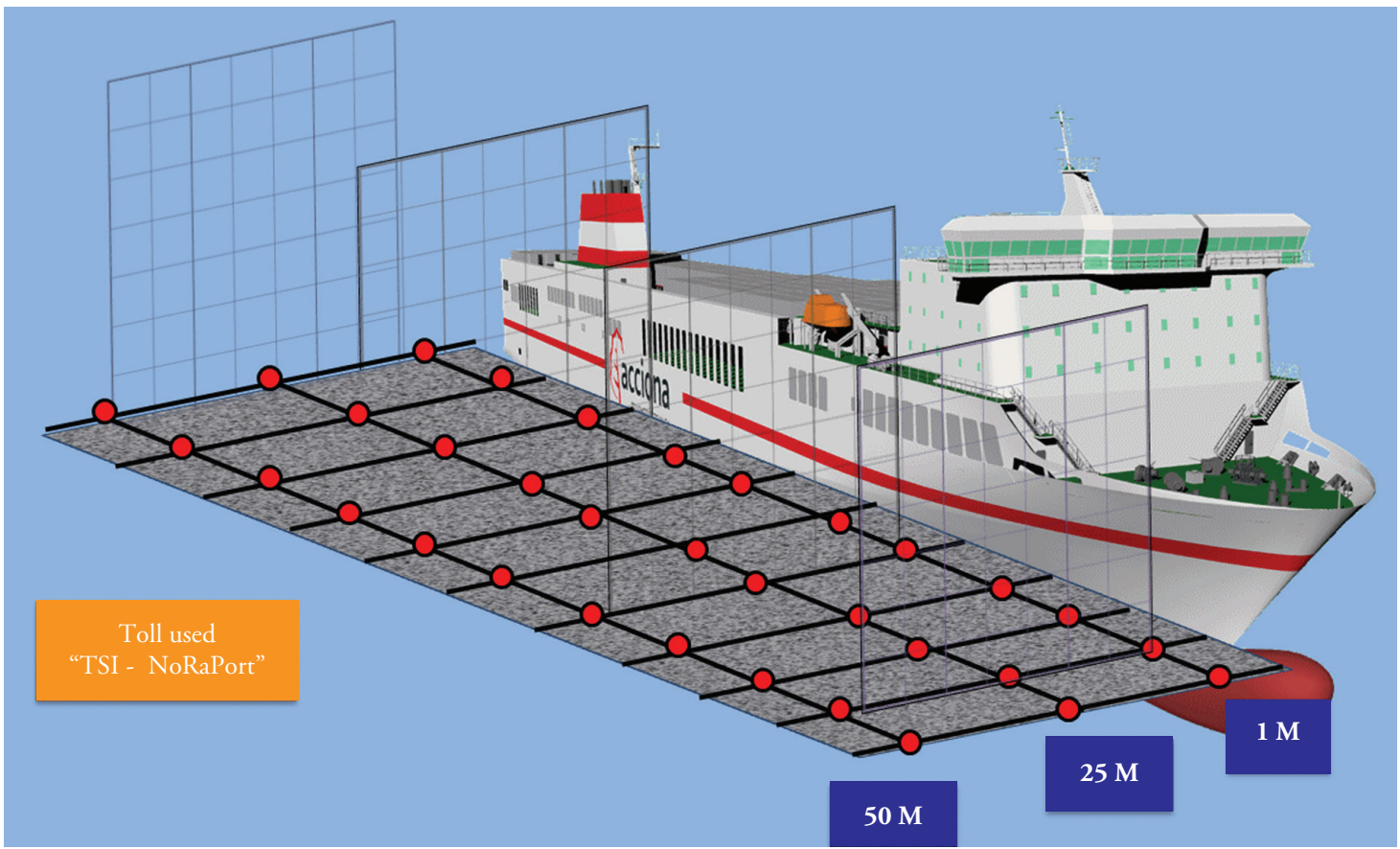




\section{Acoustic ORIGINAL Design of Fans. Obtained Results.}

The corrections experimentally obtained through FAT tests (Factory Acceptance Tests), as security margins, it was proceeded to do the first prediction of Noise Radiated to Harbour calculation with the Original Acoustic Design of Fans and Silencers. In Fig.13 it is represented the distribution of the resonant weighted pressure level (A), at quay level for port and starboard sides. The represented coloured map was obtained considering 3 distances of calculation, from each of the vessel sides, $\mathbf{1}$ meter, $\mathbf{2 5}$ meters and $\mathbf{5 0}$ meters. With the arrows graphs we represented the gradient of pressure levels from the quay side according to the obtained results.
The analysis of the previously exposed results shows that the expected pressure level EXCEEDS in $+\mathbf{1 1}$ dB (A) the contractual required levels.

For the optional condition analysed (at $1 \mathrm{~m}$ from the side) out of the Specification, in the same operational conditions as the previous case vessel, the expected noise pressure levels resultant EXCEEDS in $+\mathbf{1 8} \mathrm{dB}(\mathrm{A})$ the level of $\mathbf{8 0 ~} \mathrm{dB}(\mathrm{A})$ at $1 \mathbf{m}$ from the side.

\section{Acoustic MODIFIED Design of fans. Obtained Results.}

Based on the deficient results obtained in the prediction of the noise radiated to the harbour with the Original Acoustic Fan Design, the

Fig. 13. Original Model. Noise Radiated to the Port. Starboard and Port Side
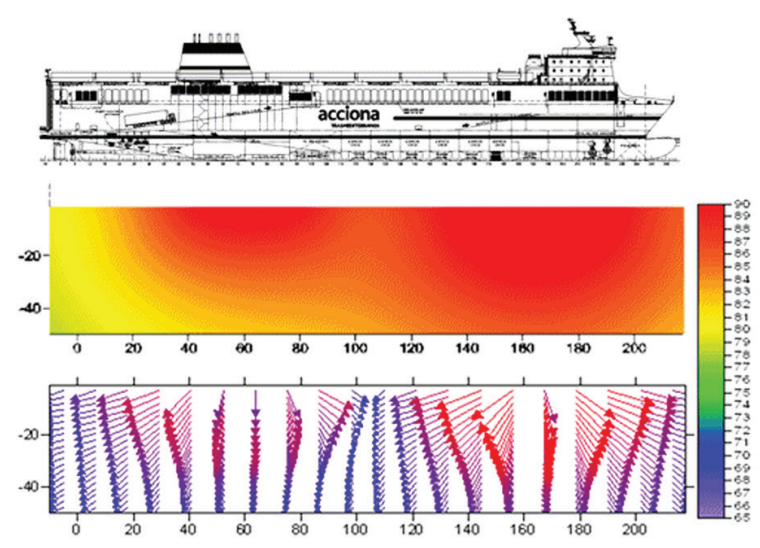

Fig. 14. Optimization at 25m. Noise Radiated to Port Distribution. Starboard and Port Side
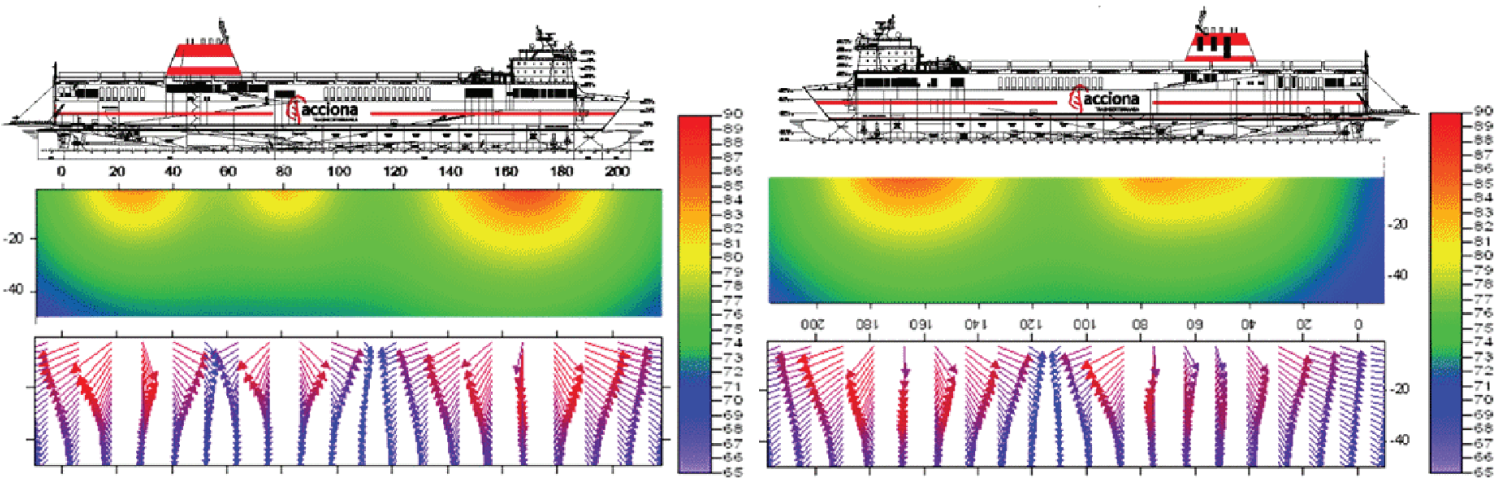

company responsible for the calculation of noise and vibration and exterior noise prediction knowing the needs of the ship-owner and of the

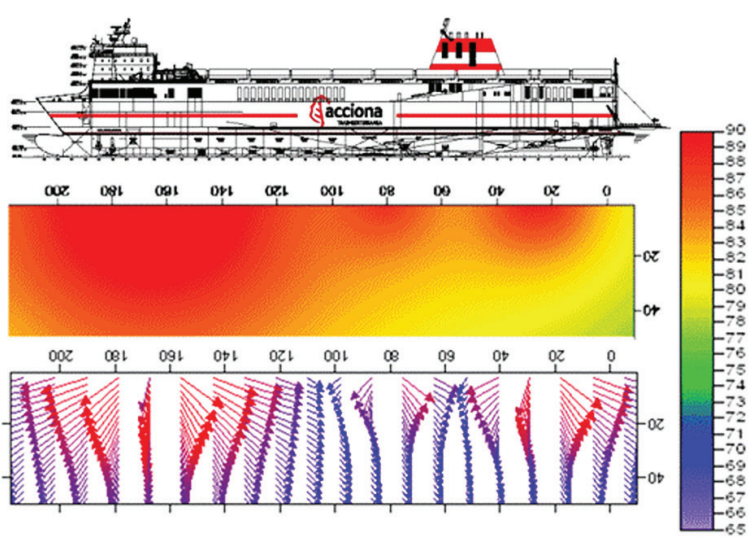


the silencers: a First Level of actions that we will call Optimization at $25 \mathrm{~m}$ and a Second Level of action called Optimization at $\mathbf{1 m}$. In Fig. 14 are shown the results obtained in the Optimization at $25 \mathrm{~m}$.

As it can be seen in the analysis of them, with the first action, level noise radiated to harbour by the C-509/510 fulfilled, for both sides of the vessel, with the $80 \mathrm{~dB}(\mathrm{~A})$ limits required in the Specification. The application of the recommendations of the Second Level corresponding to Optimization at $\mathbf{1} \mathbf{~ m}$ of the side, has conducted to the results collected in Fig. 15.

As it can be seen in the analysis of Fig. 16 with the Second Level of action, noise radiated to harbour by $\mathbf{C - 5 0 9 / 5 1 0 ~ f u l f i l l e d , ~ f o r ~ b o t h ~ s i d e s ~ o f ~ t h e ~ v e s s e l , ~}$ with the $80 \mathrm{~dB}(\mathrm{~A})$ limits required. As this option: Optimization at $1 \mathrm{~m}$ meant an "indisputable improvement" of the vessel features, as it implied not only guaranteeing the fulfillment of the Noise and Vibration Specifications but also with the adaptations of it to the in force more recent Directives, its application was constrained by the decision of NAVANTIA-Puerto Real.

\section{Sea Test in NAVANTIA- Puerto Real C-509/510: Correlation Model/ Tests}

Aimed at verifying the fulfillment of the Contractual Specification in the noise and vibration sections, before delivering each of the C-509 and C-510, TSI developed (as the consulting company

Fig. 15. Optimization at 25m. Noise Radiated to Port Distribution. Starboard and Port Side
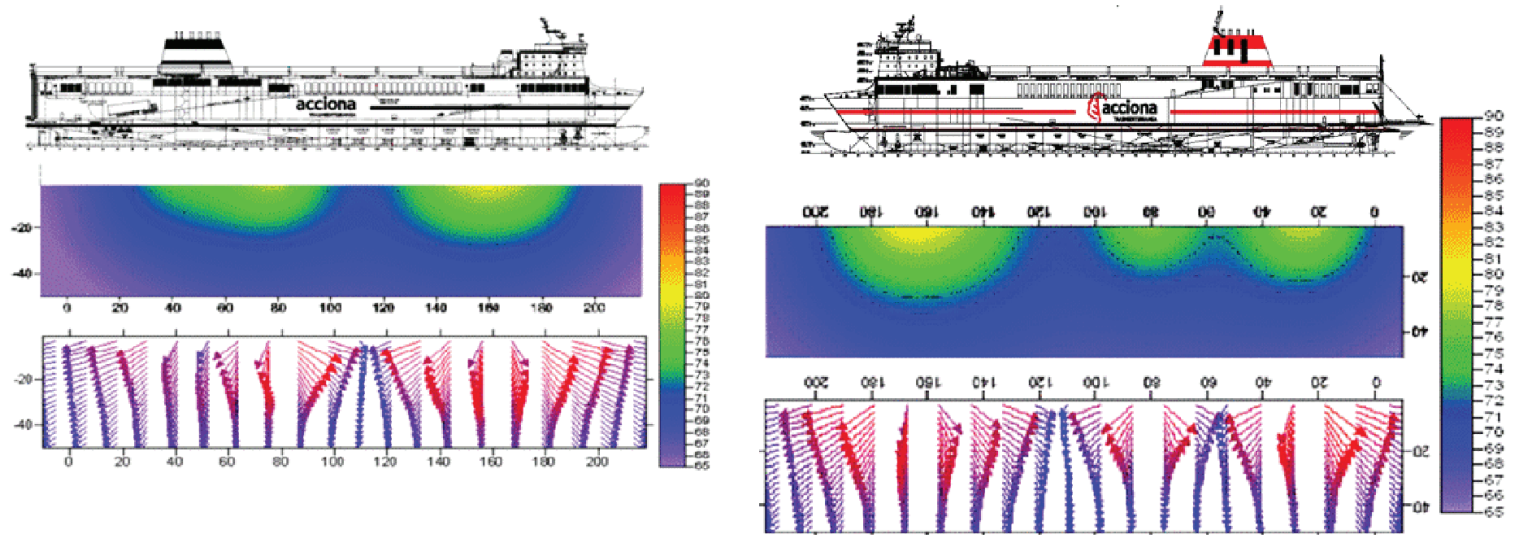

Fig. 16a. Optimization at $1 \mathrm{~m}$. Distribution of the Pressure Levels at 1 and $25 \mathrm{~m}$ length

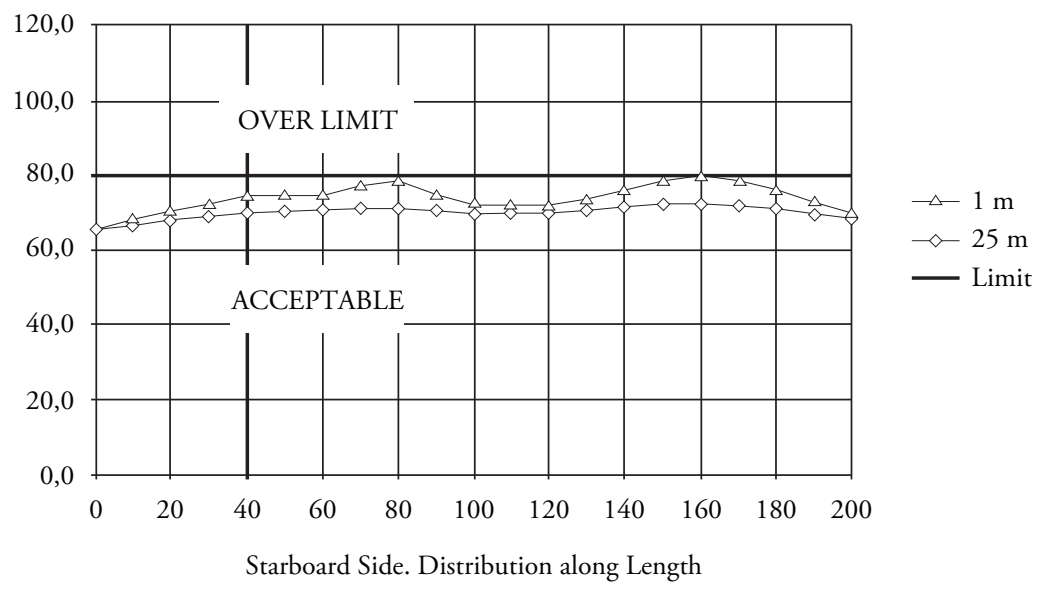


Fig. 16b. Optimization at $1 \mathrm{~m}$. Distribution of the Pressure Levels at 1 and $25 \mathrm{~m}$ length

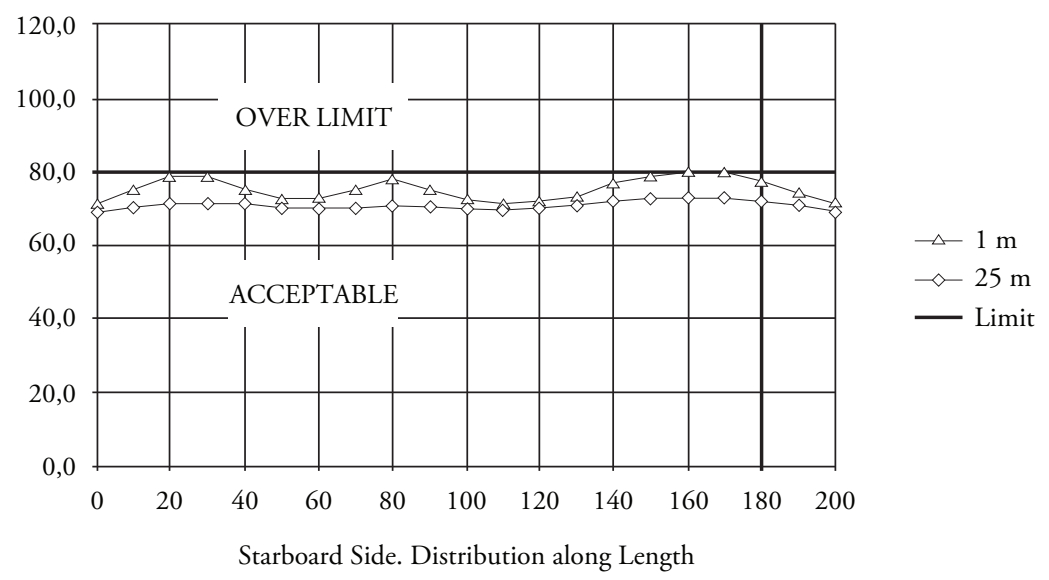

in charge of the Noise and Vibration Integrated Management), with the previous elaboration of the corresponding protocols accepted and approved by the ship-owner and the shipyard, a program of sea trials that included structural and local noise and vibrations measurement in the main equipment.

The experimental results obtained in this program of Official Tests, which will be summarized in the following sections, will help us to evaluate the goodness and efficiency of the noise and vibration predictive calculations applied.

\section{Vibrations Results}

In Fig. 17 there is a summary of the vibration levels obtained in the different areas: machines and working spaces, public spaces and crew \& passenger cabins, of the Ro-Ro's vessels "José María Entrecanales" and "Super-Fast Baleares", measured during the sea trials when delivery. In those figures and for each type of space, we included the required limits in relation to ISO Standard 6954/2000 [5] that its fulfillment was included in the Specification.

From the experimental data examination of vibration levels obtained in the Official Tests of the vessels "José María Entrecanales" and "SuperFast Baleares" we can highlight the following ones:

- In both vessels, vibration levels obtained in the different localization are well below the required limits in the ISO Standard 6454/2000 [5].

- In both vessels the IMPROVEMENTS (deviation respect the limits) obtained oscillate between $62 \%$ and $71 \%$ below the contractual limits.

- In a general way, vibration levels obtained in both vesels during the sea trials allow us to confirm that the "Dynamic design" in both constructions delivered by NAVANTIAPuerto Real, designed by SENER and calculated by the authors, fulfilled satisfactorily the Specification requirements (ISO 6954/2000 [5]) even being able to opt for a Comfort Class 2.

\section{Noise Results}

In Fig. 18 there is a summary of noise levels in different areas: machines and working spaces, public spaces and crew \& passenger cabins, of the Ro-Ro's vessels "José María Entrecanales" and "Super-Fast Baleares", measured during the official tests when delivery. In those figures and for each type of space, we included the required limits in relation to IMO A. 468(XII) Regulation [4] that its fulfillment was included in the Specification.

From the experimental data examination, of noise levels obtained in the sea trials of the vessels "José María Entrecanales" and "Super-Fast Baleares", 
Fig. 17. Vibration Levels obtained at different Locations

“JOSÉ MARÍA ENTRECANALES” - Machinery \& Work Spaces

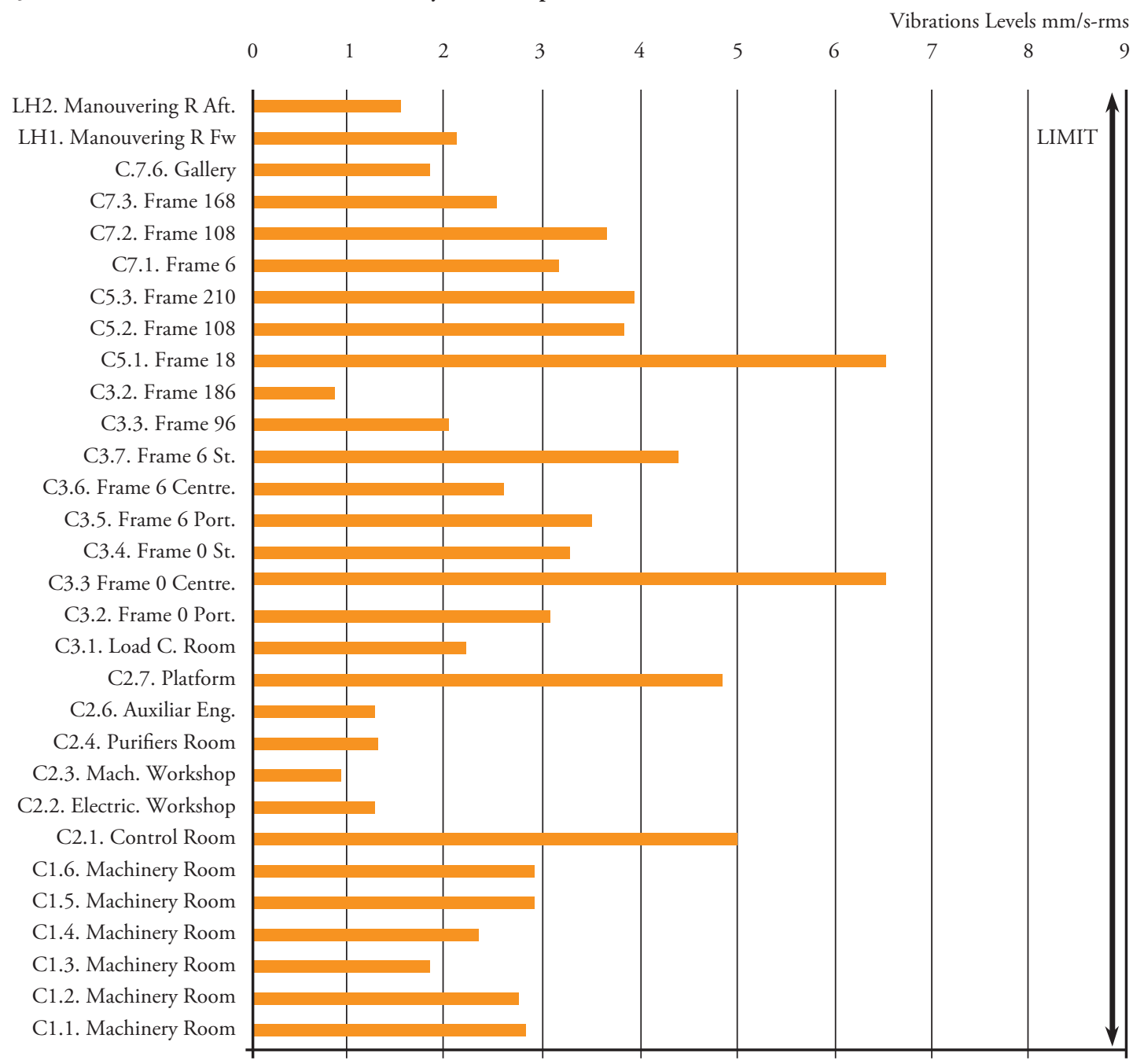

“JOSÉ MARÍa ENTRECANALES” - Public Spaces

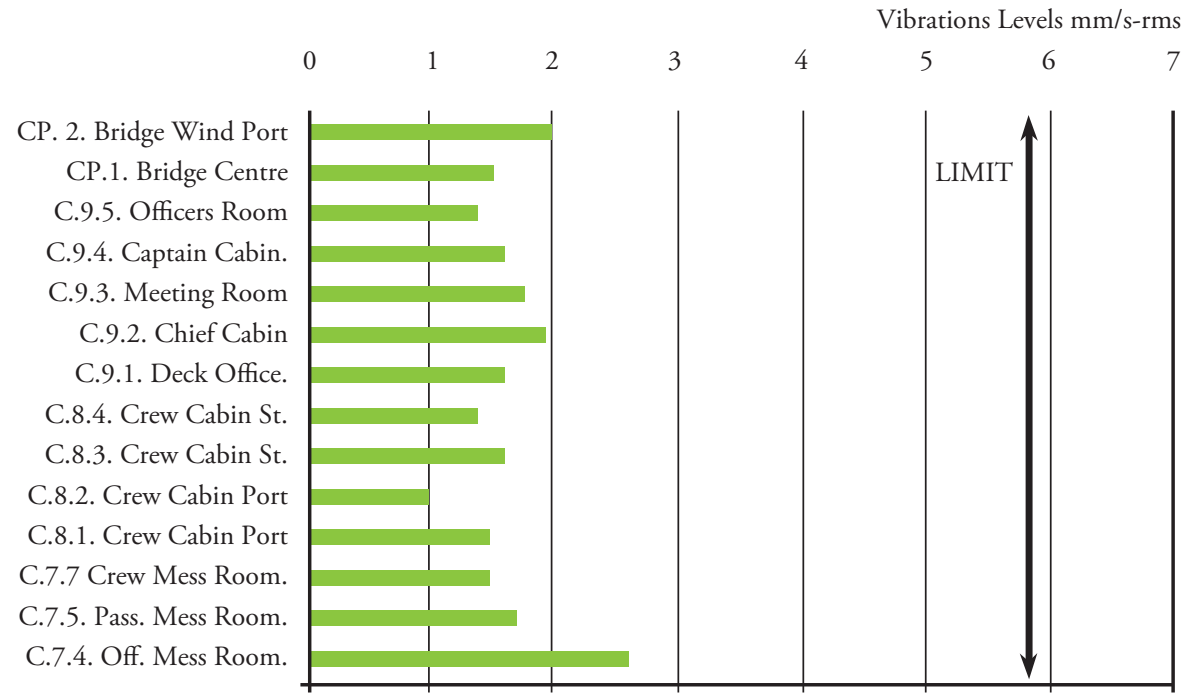


Fig. 18. Noise Levels obtained at different Locations

“JOSÉ MARÍA ENTRECANALES” - Machinery \& Work Spaces

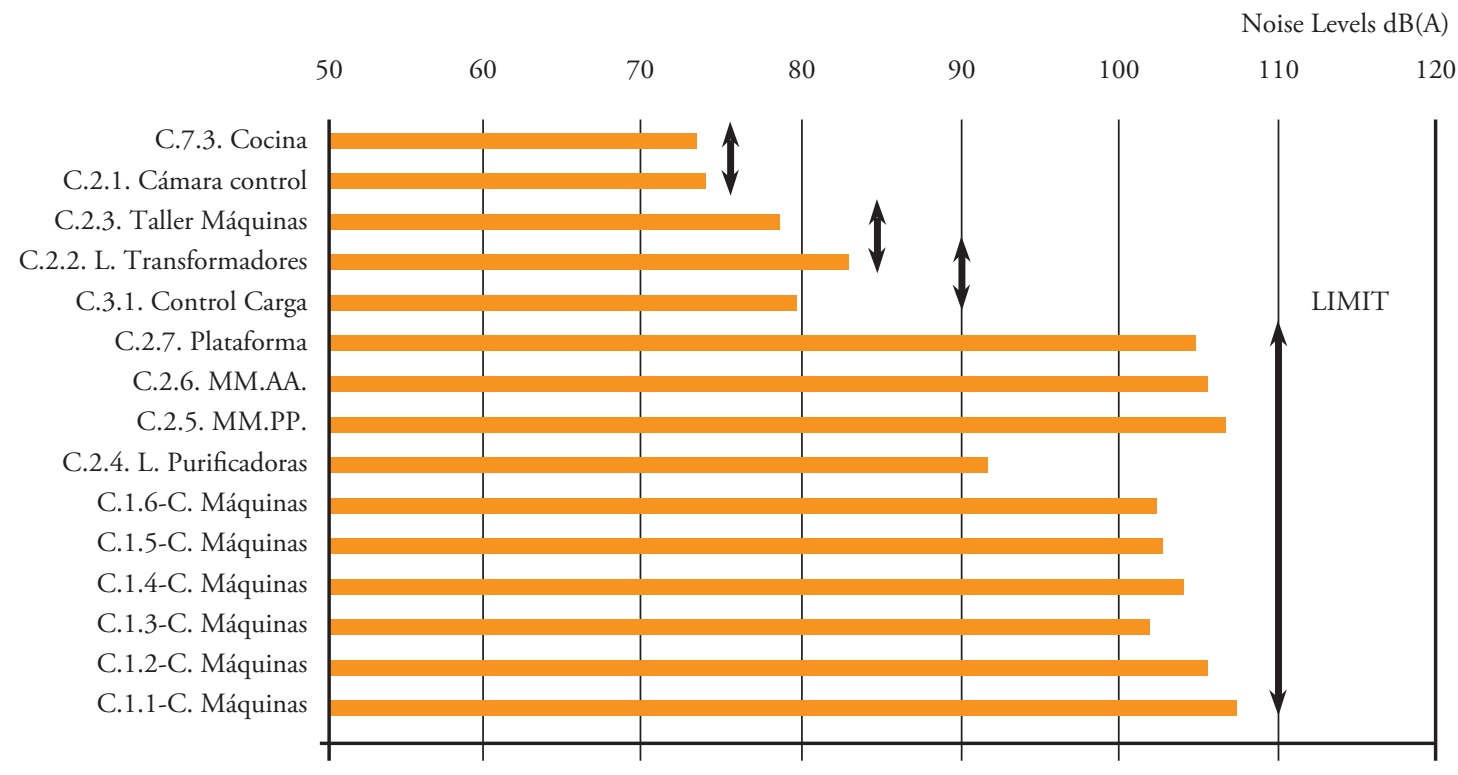

“JOSÉ MARÍA ENTRECANALES” - Passenger \& Crew Cabins

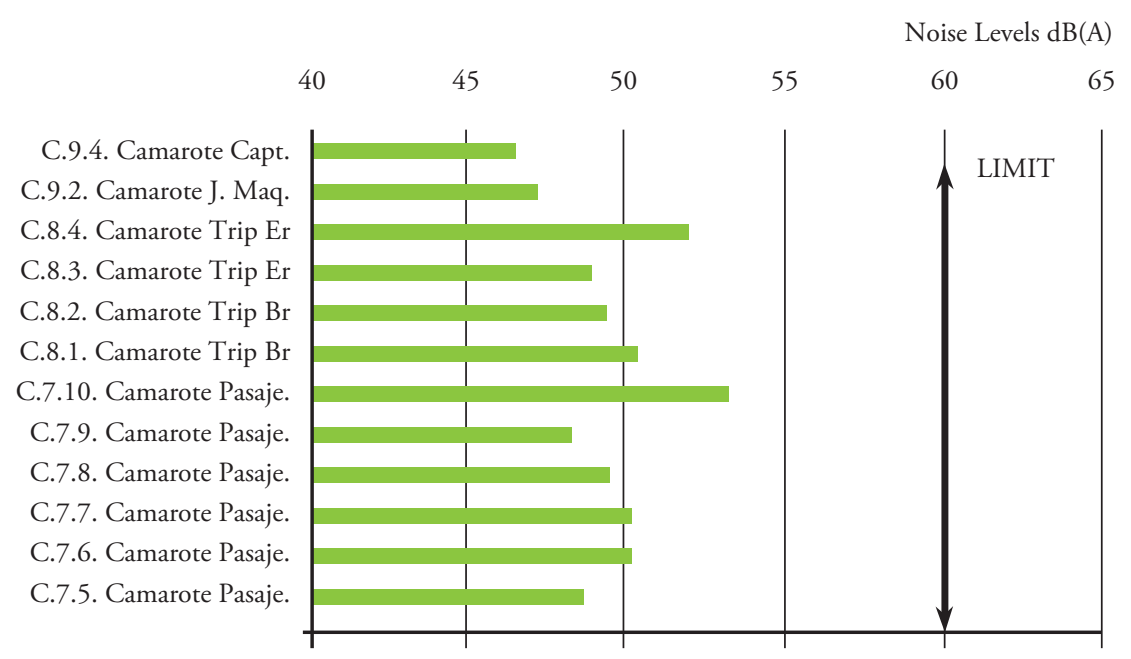

we can also highlight the following ones:

- In both vessels, noise levels obtained in the different localizations are well below the required limits in the IMO A.468 (XII) Regulation [4].

- In both vessels the IMPROVEMENTS (deviation respect the limits) obtained oscillate between $-\mathbf{6 d B}(\mathrm{A})$ up to $-\mathbf{1 1} \mathbf{d B}$ (A) below contractual limits.

- In a general way, noise levels obtained in both vessels during the official tests allow us to confirm that the "Acoustic design" in both constructions delivered by NAVANTIAPuerto Real, designed by SENER and calculated by the authors, fulfilled satisfactorily the Specification requirements (IMO A 468(XII) [5]) even being able to opt for a Comfort Class 2 or 3, in the cases that the insulation rate between cabins and public spaces accomplish the minimum requirements of the Classification Societies. 
Noise Radiated to the Harbour Results

After the results of the Tests in relation to the measures of Noise Radiated to Harbour by the vessels "José María Entrecanales" and "SuperFast Baleares" (Fig. 19), the following remarks are highlighted:
- In both vessels the Noise Radiated to Harbour level at $25 \mathrm{~m}$ for each side ARE WELL BELOW the 80 dB (A) limits required in the Specification.

- Also the IMPROVEMENTS (deviation respect the limits) obtained oscillate between $-8.5 \mathrm{~dB}(\mathrm{~A})$ and $-15.2 \mathrm{~dB}(\mathrm{~A})$ for starboard

Fig. 19. Assessment of the OPTIMIZATION at $1 \mathrm{~m}$

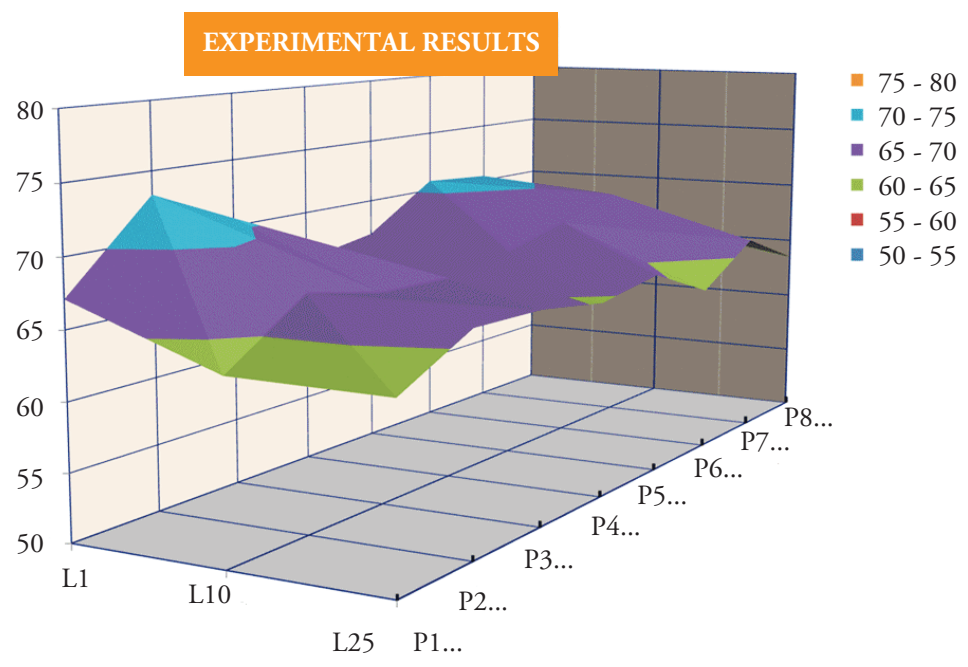

Fig. 20. Correlation: Exterior Noise Radiated Model/Tests" for C-509 at $1 \mathrm{~m}$ from the side
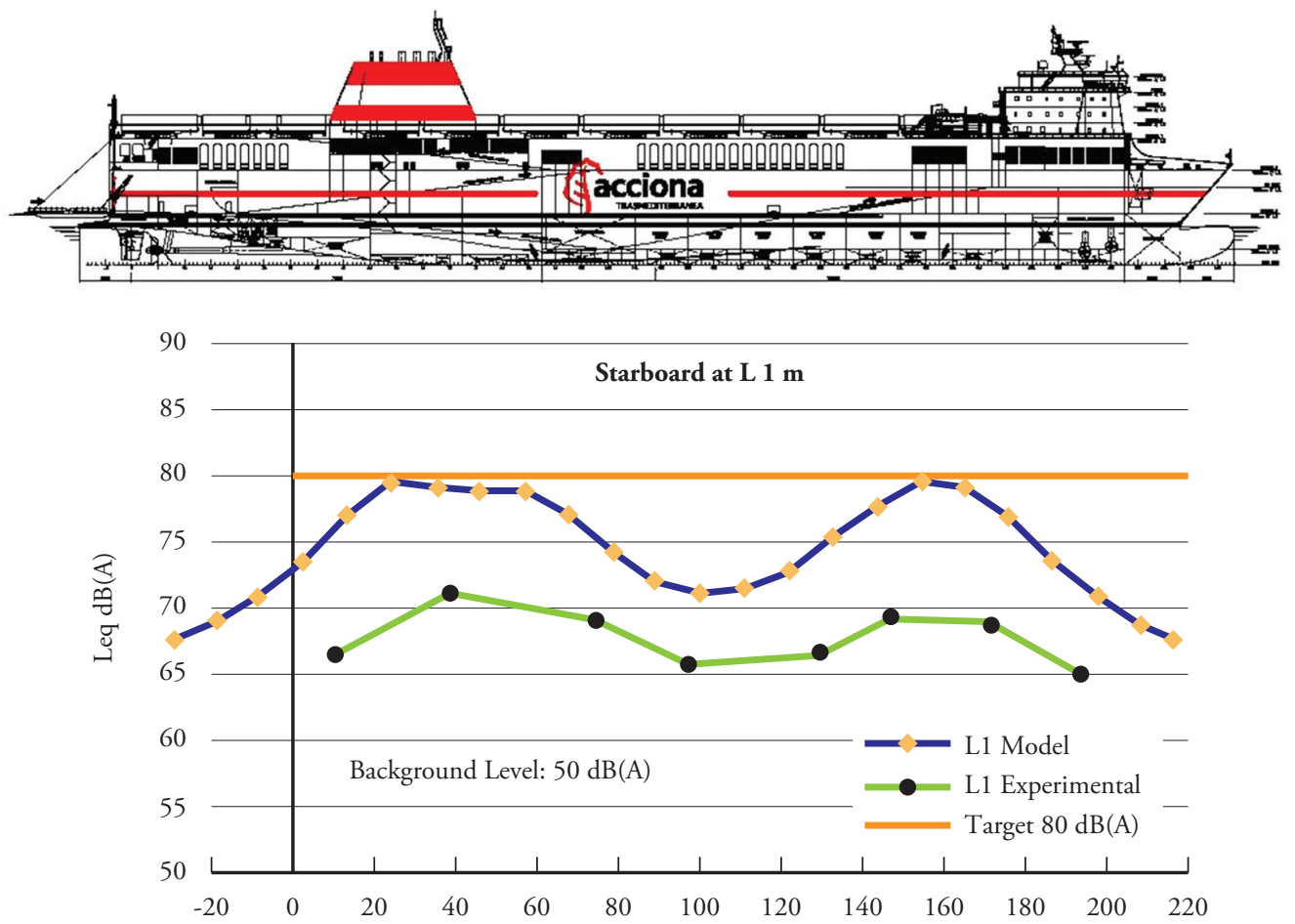

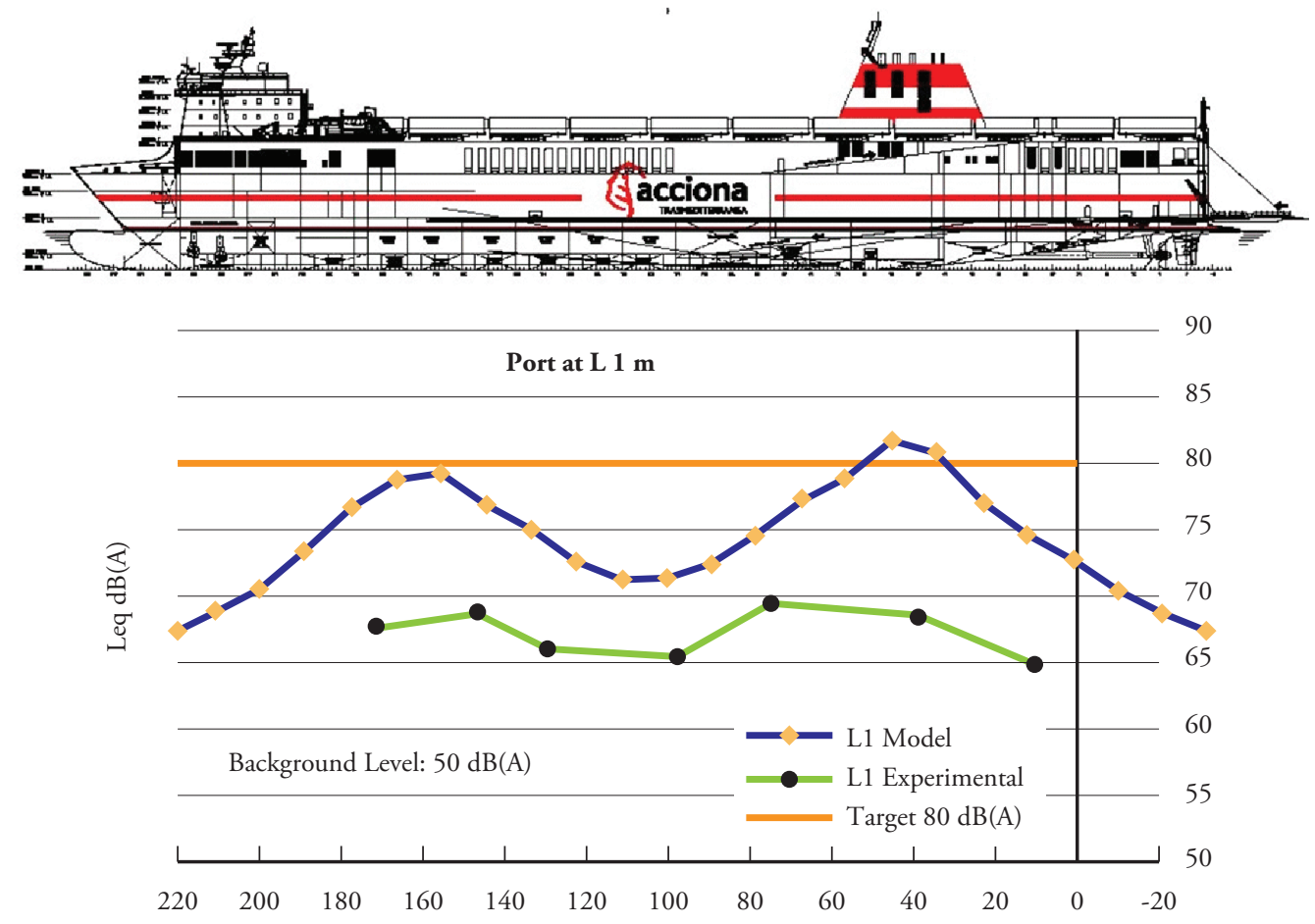

side and between $-11.5 \mathrm{~dB}(\mathrm{~A})$ and - 15.6 $\mathrm{dB}$ (A) for port side, ARE WELL BELOW THE CONTRACTUAL LIMITS.

Noise and Vibration Predictions can be considered "solid" tools due to several publications about "Model-Test Correlation" that are endorsed by the experience of the authors in the Silent Vessels and the Oceanographic Vessels, in which they have participated $[10,11,12,13]$. With the new requirement of Noise Radiated to Harbour by vessels, it is necessary that the applied "calculation tools" used must be contrasted with the experimental results obtained. Fig. 20 shows the results of this "Correlation: Exterior Noise Radiated Model/Tests" for C-509 at $1 \mathrm{~m}$ from the side.

Analysing these figures it is possible to confirm that this is a "Solid, consistent and conservative tool to predict Noise Radiated to the Harbour by the vessel" as the expected calculation results are between $+\mathbf{5}$ and $+\mathbf{1 0} \mathbf{~ d B}(\mathrm{A})$ over the values experimentally obtained. Security margins which could be taken as appropriate in noise prediction.

\section{Conclusions: Lessons learnt}

As it is normal in this type of articles, we present Conclusions and "our professional experiences related to this work" as Lessons learnt that we modestly submit to sea professionals, in order to enrich this with their contributions and comments and, definitely, to be able to improve the quality and competitiveness of our Marine Sector. Some of the most interesting ones, according to our judgement, are detailed in the following items:

- The recent delivery of the RO-RO vessels "José María Entrecanales" and "Super-Fast Baleares" to ACCIONA TRANSMEDITERRÁNEA, designed by SENER and built by NAVANTIA-Puerto Real, with vibration levels well below (67\%) the ISO 6954/2000 [5] established limits, noise levels $-8 \mathrm{~dB}$ (A) below the recommended limits in the IMO A.468 (XII) [4], and finally, noise radiated to harbour levels within the realm of $15 \mathrm{~dB}$ (A) below the $80 \mathrm{~dB}$ (A) limit required not only in the Specification but also 
in the Community Directives, in force, such as 2002/49/EC [2], achieving an unprecedented fact and becoming an additional technological milestone in the Marine Spanish Sector.

- The quality of the obtained final product allows NAVANTIA-Puerto Real to reaffirm its position in the selected "market niche" of "Silent Vessels", and also, to have a "technically supported reference", in national and international markets where, currently, there is a high demand of these types of vessels.

- The introduction of this Regulatory Framework, due to the fact that it "obliges" the Ship-owners and the managers of the vessel operating companies, in the Specifications is occurring. Well evidenced in the most recent Specifications of all types of vessels in which the author is involved.

- This fact that, some could consider "a problem", the author believes that if we are clever enough it could become a "new business opportunity" in our Marine Sector. The author, from his experience with his participation in the R\&D European projects (SILENV AND BESST) more avant-garde in these aspects, thinks that more would be the advantages than the disadvantages when applying an "efficient technical answer" to the new Regulatory Framework. All of the European shipyards (our neighbours) that participated in these projects understood it in this way and their movements are going in this direction.

- For those who may feel "frightened" in view of this new Regulatory Framework, that is already included in the Contractual Specification of the vessels, or for those who prefer "looking at the other side" facing this new unquestionable reality, we would like to tell them that the answer to the question: Is the National Marine Sector ready to respond to these new and strict requirements? Is definitely YES, it is ready.

- In few words, "we know how to do it". We only need to "know how to sell it". It is a hard task but based on our extended experience as a "survival SME" we would like to provide some ideas:

- Ship-owners, nationals and foreigners, must know and understand our skills to help them with guarantees in the fulfilling of the new Regulatory Framework that they are forced too. For this: 1) We must "make noise", this means, our achievements in the sector should appear in foreign publications. 2) Our commercial colleagues must, besides knowing the new Directives and their technical and economic implications in the vessel price know and have a value enhancement strategy.

- We must know that our guarantees on fulfilling depend on the appropriate tools that we use: Noise and Vibration Integrated Management, "contractual commitment" from the suppliers with the shipyard and ship- owner's objectives, data verification provided by reception test in the factory acceptance test (we should not forget that the "absence or inaccuracy" will be paid by the shipyard), we use insulation standardize material (pay now or pay later) and its correct assembly, etc. All this undoubtedly "add" and must be considered when making the shipyard understand.

- Finally, these new Directives are seen by some with fear, due to the implications when coming into force. In view of this scene, let's "have a look at" other sectors and see what they have done. In concrete, Automobile Sector, in view of the Community Regulations and Directives of emissions reduction, which scared some, what did they do?, acting as a "lobby", they decided to invest in all the technical improvements to meet the targets, they knew how to make a good "business opportunity" out of what others considered "a problem": "Prever plan" (financed by EU) and the complete renovation, in ten years, of all car fleet in all the European countries. In conclusion "BUSINESS OPPORTUNITY". 


\section{References}

[1] European Commission Green Paper on Future Noise Policy (COM (96) 54 540). 1996.

[2] Directive 2002/49/EC of the European Parliament and of the Council of 25 June 2002 relating to the assessment and management of environmental noise.

[3] BELTRÁN P; TESORERO M. ANTONIA, "Spanish Shipbuilding ready to meet the new and demanding Environmental Requirements: New Challenges and Business Opportunities" Ingeniería Naval No. 887, December. [4] IMO Resolution A.468 (XII): Code on Noise Levels on Board Ships. IMO 1975.

[5] ISO 6954:2000: Mechanical vibration Guidelines for the measurement, reporting and evaluation of vibration with regard to habitability on passenger and merchant ships.

[6] ISO 2922/2000 Acoustics -- Measurement of airborne sound emitted by vessels on inland waterways and harbours.

[7] ICES Cooperative Research Report No. 209. Underwater noise of research vessels, review and recommendations. ISSN 1017-6195, May 1995.

[8] ANSI/ASA S12.64-2009/Part 1: Quantities and Procedures for Description and Measurement of Underwater Sound from Ship - Part 1: General Requirements.

[9] DNV Rules for Classification of Ship. New buildings, Special Equipment and Systems
Additional Class: Part 6, Chapter 24 Silent Class Notation, January 2010.

[10] BELTRÁN P., "Noise vibration on ship prediction: Basic engineering tool to fulfill the current requirements of comfort and quality". Naval Engineering, October 2001.

[11] BELTRÁN P. AND OTHERs, "Silent Fishing Vessels. A milestone for small and big Spanish shipyards. Lessons learnt.". Separata Naval Engineering, February 2.006.

[12] BELTRÁN P., "Oceanographic ship Miguel Oliver". Naval Engineering No. 848, May 2007.

[13] BELTRÁN P. "Oceanographic Ship "Miguel Oliver": The excellence on Noise and Vibration on board fulfilling ICES- Na209. First Prize 47th Congress of Naval Engineering and Maritime Industry. October 2008.

[14] ENCISO FERNÁNDEZ, C., "About noise and vibration transmission in the MAPA 70 of M. Cies shipyard" Naval Engineering. May 2007.

[15] PÉREZ GÓMEZ G., PÉREZ SOBRINO M., GONZÁLEZ-ADALID J., GARCÍA GÓMEZ A., MASIP HIDALGO J., QUEREDA LAVIÑA R., MINGUITO CARDEÑA E., BELTRÁN P., "A milestone in the Spanish naval propelling. Profitability of a wide $\mathrm{R} \& \mathrm{D}$ program. $75^{\text {th }}$ Anniversary Award. AINE. Naval Engineering, June 2006. 